Supporting Information for

\title{
Vinyl-Addition Polymerizations of Borylated Allenes
}

Brian P. Jacobs and Johnathan N. Brantley

Department of Chemistry, University of Tennessee, Knoxville, Tennessee 37916

\section{Email: jbrant13@utk.edu}

\section{Table of Contents}

1 General Considerations $\quad$ S4

1.1 Materials and Methods $\quad$ S4

2 Polymerization Studies $\quad$ S5

2.1 Catalyst Screen for Polymerization of Monomer 1

2.2 Solvent Screen for Polymerization of Monomer 1 with Catalyst $3 \quad$ S6

2.3 Scale-Up Preparation of Polymer 2 Under Optimized Conditions $\quad$ S6

2.4 Preparation of Polymer 2 with Various Molecular Weights $\quad$ S7

Table S1: Representative Range of Molecular Weights Accessible $\quad$ S7

2.5 Preparation of High $M_{n}$ Polymer 2 under Dilute Conditions $\quad S 7$

2.6 Preparation of Low $M_{n}$ Polymer $2 \quad$ S8

3 Determination of Living Character $\quad$ S8

3.1 Molecular Weight as a Function of Conversion S8

Table S2: Living Plot Molecular Weight and Conversion Data S9

Figure S1: Percent Conversion of Monomer 1 as a Function of Time $\quad$ S10

3.2 Chain Extension Experiment $\quad \mathrm{S} 10$

Table S3: Molecular Weight Data for Chain Extension of Polymer $2 \quad$ S11

4 Block Copolymerizations with Additional Allenes $\quad \mathrm{S} 11$

4.1 Generation of Block Copolymer $6 \quad S 11$

4.2 Generation of Block Copolymer $7 \quad \$ 12$

4.3 Replication Studies for Block Copolymerizations S13 
4.3.1 Borylated Allene 1 Polymerization Followed by Aliphatic Allene

4.3.2 Aliphatic Allene Polymerization Followed by Borylated Allene 1

Table S4: Tabulated Data for Block Copolymers from Replication Studies

S14

5 Post-Polymerization Modification

5.1 Suzuki-Miyaura Cross-Coupling of Polymer 2 with Phenyl Bromide $\quad$ S15

6 Material Characterization

6.1 GPC Traces and Thermomechanical Data of Polymer 2

S16

Figure S2: GPC Traces of Polymer 2 from Catalyst Screen

S16

Figure S3: GPC Traces of Polymer 2 from Solvent Screen

S17

Figure S4: GPC Trace of Scale-Up of Polymer 2

Figure S5: GPC Traces for Representative Molecular Weights of Polymer 2 S18

Figure S6: GPC Trace for Dilute Polymerization of Polymer 2

S18

Figure S7: GPC Trace of Low $M_{n}$ Polymer 2

S19

Figure S8: TGA Thermogram of Polymer 2

Figure S9: Powder DMA Thermogram of Polymer 2

S20

Figure S10: DSC Thermogram of Polymer 2

S20

6.2 GPC Traces for Living Character Experiments

S21

Figure S11: GPC Traces of Living Experiment

S21

6.3 GPC Traces and Thermomechanical Data of Block Copolymers

S21

Figure S12: GPC Traces of Block Copolymerization Replications

S21

Figure S13: GPC Traces of Reversed Order Block Copolymerization

S22

Figure S14: TGA Thermogram of Block Copolymer 6

S22

Figure S15: TGA Thermogram of Block Copolymer 7

S23

Figure S16: Powder DMA Thermogram of Block Copolymer 7

S23

\section{NMR Spectral Data}

S24

Figure S17: DEPTQ NMR Spectra of Polymer 2

S24

Figure S18: ${ }^{1} \mathrm{H}$ NMR Spectrum of Low $M_{n}$ Polymer 2

S25 
Figure S19: Magnified ${ }^{1} \mathrm{H}$ NMR Spectrum of Polymer 2 in $\mathrm{CDCl}_{3}$ with Integrations of Major Resonances S26

Figure S20: Magnified ${ }^{1} \mathrm{H}$ NMR Spectrum of Polymer 2 in $\mathrm{CDCl}_{3}$ with Integrations of Minor Resonances

Figure S21: ${ }^{11} \mathrm{~B}$ NMR Spectrum of Polymer 2

Figure S22: ${ }^{1} \mathrm{H}$ NMR Spectrum of Block Copolymer 6 S27

Figure S23: ${ }^{13} \mathrm{C}$ NMR Spectrum of Block Copolymer 6 S28

Figure S24: ${ }^{11} \mathrm{~B}$ NMR Spectrum of Block Copolymer 6 S28

Figure S25: ${ }^{1} \mathrm{H}$ NMR Spectrum of Block Copolymer 7 S29

Figure S26: ${ }^{13} \mathrm{C}$ NMR Spectrum of Block Copolymer 7 S29

Figure S27: ${ }^{11} \mathrm{~B}$ NMR Spectrum of Block Copolymer 7 S30

Figure S28: ${ }^{1} \mathrm{H}$ NMR Spectrum of 6 From Replicated Protocol S30

Figure S29: ${ }^{1} \mathrm{H}$ NMR Spectrum of 7 From Replicated Protocol S31

Figure S30: ${ }^{1} \mathrm{H}$ NMR Spectrum of 6 From Reverse Addition Protocol

Figure S31: ${ }^{1} \mathrm{H}$ NMR Spectrum of 7 From Reverse Addition Protocol S32

Figure S32: ${ }^{1} \mathrm{H}$ NMR Spectrum of Cross-Coupling Product 8 S32

Figure S33: ${ }^{13} \mathrm{C}$ NMR Spectrum of Cross-Coupling Product 8 


\section{General Considerations}

\subsection{Materials and Methods}

Unless otherwise noted, solvents were dried on an MBraun solvent purification system with $3 \AA$ molecular sieves and degassed with three freeze pump thaw cycles. Monomer allenyl pinacol boronic ester 1 was either purchased from commercial sources and used without further purification, or was prepared from literature reports. ${ }^{1}$ Catalyst 5 [trans$\left.\left(\mathrm{C}_{6} \mathrm{~F}_{5}\right)_{2} \mathrm{Ni}\left(\mathrm{SbPh}_{3}\right)_{2}\right]$ was prepared from a literature report. ${ }^{2}$ Comonomers 1,2-nonadiene ${ }^{3}$ and $\beta$-pinadiene ${ }^{4}$ were prepared from literature reports. All other reagents were obtained from commercial sources and used without further purification. Oxygen and water sensitive manipulations were performed in a $\mathrm{N}_{2}$ filled MBraun glovebox or using standard Schlenk techniques. All polymerizations were performed in a $\mathrm{N}_{2}$ filled MBraun glovebox. ${ }^{1} \mathrm{H},{ }^{11} \mathrm{~B}$, and ${ }^{13} \mathrm{C}$ NMR spectral data were collected on a Varian $500 \mathrm{MHz} \mathrm{NMR}$ spectrometer. Chemical shifts $(\delta)$ for spectra are reported in ppm using the residual solvent as reference $\left({ }^{1} \mathrm{H}\right.$ and $\left.{ }^{13} \mathrm{C}\right)$ or no reference $\left({ }^{11} \mathrm{~B}\right) .{ }^{1} \mathrm{H}$ and ${ }^{13} \mathrm{C}$ spectra acquired in $\mathrm{CDCl}_{3}$ solvent contain tetramethylsilane as an internal standard $\left(0.08 \mathrm{ppm}\right.$ in ${ }^{1} \mathrm{H} ; 1.18$ ppm in ${ }^{13} \mathrm{C}$ ). Gel Permeation Chromatography (GPC) data were collected on an Omnisec Resolve and Omnisec Reveal System using triple detection with detectors in series: UV, light scattering, viscometer, and refractive index and three Viscotek styrene divinylbenzene copolymer columns (in series T3000, T4000, and T5000) at a flow rate of $1 \mathrm{~mL} / \mathrm{min}$ and thermostatted to $30^{\circ} \mathrm{C}$ using tetrahydrofuran (THF) as the eluent. Triple detection molecular weight and dispersity data are reported. Thermogravimetric Analysis (TGA) was performed on a TA Instruments TGA Q500, Dynamic Mechanical Analysis (DMA) data was collected on a TA Instruments DMA Q800 with a powder clamp, and Differential Scanning Calorimetry (DSC) data was collected on a TA Instruments Q-2000 DSC equipped with a refrigerated cooling system and standard aluminum pans. 


\section{Polymerization Studies}

\subsection{Catalyst Screen for Polymerization of Monomer 1}

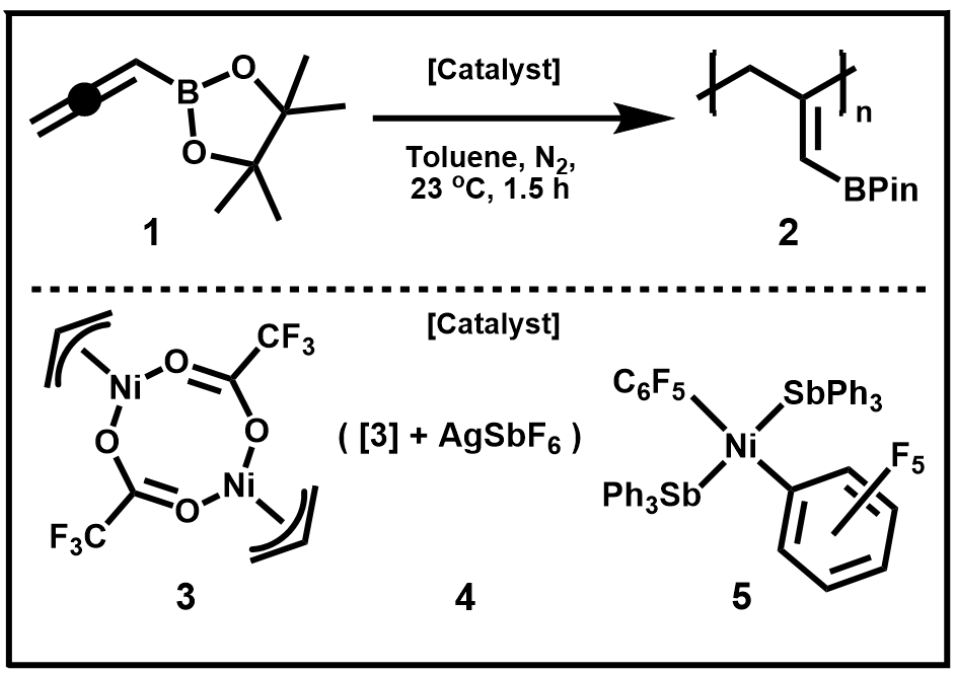

A 2-dram vial was charged with the monomer allenyl boronic pinacol ester 1 (100 $\mathrm{mg}, 0.6 \mathrm{mmol}$ ) and 1.1 $\mathrm{mL}$ toluene. The solution was stirred at $23^{\circ} \mathrm{C}$ for 5 minutes, after which a toluene solution of the tested catalyst was added to the solution $(0.0033 \mathrm{mmol}[\mathrm{Ni}$; ; target $\boldsymbol{M}_{\boldsymbol{n}}=30,000 \mathrm{Da}$; details of catalyst solution preparation given after the general polymerization method). The resultant mixture was stirred at $23^{\circ} \mathrm{C}$ for $1.5 \mathrm{~h}$ in the absence of light, after which the reaction was quenched via exposure to air. The mixture was concentrated to dryness on a Schlenk line, and the isolated polymer 2 was dried in a vacuum oven set to $100^{\circ} \mathrm{C}$ overnight. The yield was determined for each successful polymerization, and GPC data was acquired. Each test polymerization was conducted in triplicate. Recorded yields and GPC data are presented in Table 1, and GPC traces are provided in Figure S2.

Catalyst 3 Preparation: ${ }^{5}$ A 2-dram vial was charged with $\mathrm{Ni}(\operatorname{cod})_{2}(25 \mathrm{mg}, 0.091 \mathrm{mmol}$; $\mathrm{cod}=1,5$-cyclooctadiene $)$ and $3.5 \mathrm{~mL}$ toluene. Allyl trifluoroacetate $(11.7 \mu \mathrm{L}, 0.090 \mathrm{mmol})$ was syringed into the solution, and the color transitioned to red-orange upon dissolution of the $\mathrm{Ni}(\mathrm{cod})_{2}$. For the catalyst screen, $0.13 \mathrm{~mL}$ of the solution of catalyst $3(0.026 \mathrm{M}$, $0.0033 \mathrm{mmol}[\mathrm{Ni}]$ ) was added to the solution of monomer 1 .

Catalyst 4 Preparation: ${ }^{2}$ To start the preparation of catalyst $4,0.13 \mathrm{~mL}$ of the toluene solution of $3(0.026 \mathrm{M})$ was added to a 1-dram vial. To the vial was added $\mathrm{AgSbF}_{6}(2.3$ $\mathrm{mg}, 0.0067 \mathrm{mmol}[\mathrm{Ni}])$, resulting in deposition of a brown solid and a dark solution of catalyst $\mathbf{4}$. This solution was added to the solution of monomer $\mathbf{1}$ for the catalyst screen.

Catalyst 5 Preparation: ${ }^{2}$ A 1-dram vial was charged with trans $-\left(\mathrm{C}_{6} \mathrm{~F}_{5}\right)_{2} \mathrm{Ni}\left(\mathrm{SbPh}_{3}\right)_{2}(3.6 \mathrm{mg}$, $0.0033 \mathrm{mmol}[\mathrm{Ni}]$ ) and $0.13 \mathrm{~mL}$ toluene. After dissolution of catalyst $\mathbf{5}$, the solution was added to the solution of monomer $\mathbf{1}$ for the catalyst screen. 


\subsection{Solvent Screen for Polymerization of Monomer 1 with Catalyst 3}

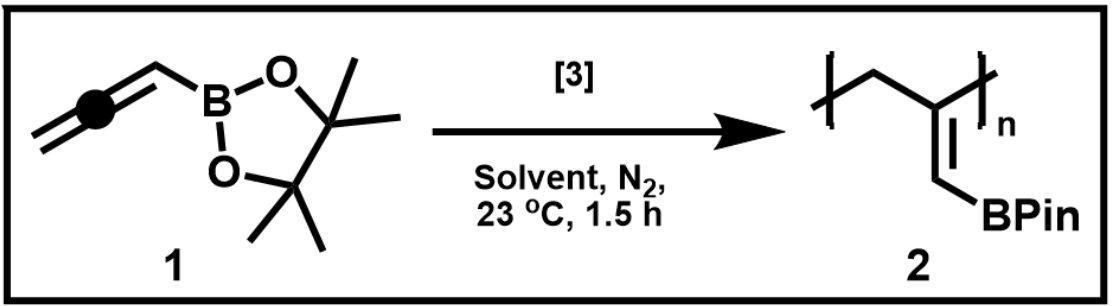

A 2-dram vial was charged with monomer 1 (100 $\mathrm{mg}, 0.6 \mathrm{mmol}$ ) and $1.1 \mathrm{~mL}$ of a selected solvent (see below). The solution was stirred at 23

${ }^{\circ} \mathrm{C}$ for 5 minutes, after which $0.13 \mathrm{~mL}$ a toluene solution of catalyst 3 was added to the solution ( $0.026 \mathrm{M}, 0.0033 \mathrm{mmol}\left[\mathrm{Ni}\right.$; t target $\left.M_{n}=30,000 \mathrm{Da}\right)$. The resultant mixture was stirred at $23^{\circ} \mathrm{C}$ for $1.5 \mathrm{~h}$ in the absence of light, after which the reaction was quenched via exposure to air. The mixture was concentrated to dryness, and the isolated polymer 2 was dried in a vacuum oven set to $100^{\circ} \mathrm{C}$ overnight. The yield was determined for each successful polymerization, and GPC data was acquired. Four solvents were evaluated simultaneously in separate reactions ( $\mathrm{THF}, \mathrm{Et}_{2} \mathrm{O}, \mathrm{CDCl}_{3}$, and $\mathrm{DCM}$ ). Recorded yields and GPC data are presented in Table 1, and GPC traces are provided in Figure S3.

\subsection{Scale-Up Preparation of Polymer 2 Under Optimized Conditions}

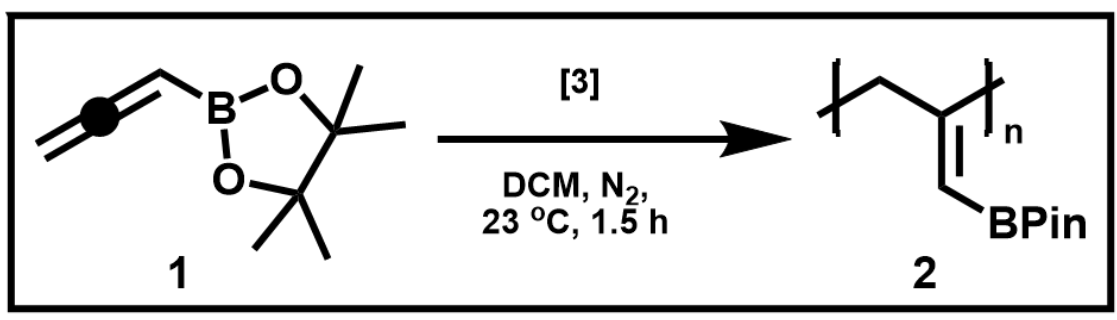

A $50-\mathrm{mL}$ oven-dried Schlenk flask was charged with monomer 1 $(2.000 \mathrm{~g}, 12.05 \mathrm{mmol})$ and $24 \mathrm{~mL}$ DCM. A separate 2-dram vial was

charged with $\mathrm{Ni}(\operatorname{cod})_{2}(18.3 \mathrm{mg}, 0.0665 \mathrm{mmol}), 2.6 \mathrm{~mL}$ toluene, and allyl trifluoroacetate $\left(8.8 \mu \mathrm{L}, 0.067 \mathrm{mmol}\right.$; target $\left.M_{n}=30,000 \mathrm{Da}\right)$. The solution of catalyst 3 was added to the stirring solution of monomer 1 . The mixture was stirred at $23^{\circ} \mathrm{C}$ for $1.5 \mathrm{~h}$ in the absence of light. After the allotted reaction time, the polymerization was exposed to air, the mixture was concentrated to dryness, and the residue was dissolved in $5 \mathrm{~mL}$ THF. The THF solution was added dropwise to $100 \mathrm{~mL} \mathrm{DI} \mathrm{H}_{2} \mathrm{O}$, resulting in the precipitation of a faint tan solid. The solid was collected via vacuum filtration, and the solid was reprecipitated a second time in the same manner previously described. After two precipitations, the collected solid was dried in a vacuum oven set to $100^{\circ} \mathrm{C}$ overnight, yielding polymer 2 as a faint tan powder (1.9165 g, 96\% yield; 39,970 Da; 1.51 Đ). The GPC trace for the product is provided in Figure S4, and NMR spectral data were collected in $\mathrm{CDCl}_{3}$ (Figures 2 and S27). Thermomechanical characterization is provided in Figures S8-S10. ${ }^{1} \mathrm{H}$ NMR $\left(\mathrm{CDCl}_{3}\right): \delta 1.16(12 \mathrm{H}), 3.14(2 \mathrm{H}), 5.26(1 \mathrm{H}) .{ }^{13} \mathrm{C} \mathrm{NMR}\left(\mathrm{CDCl}_{3}\right): \delta 25.00,45.61,82.35$, 116.31, 161.92. ${ }^{11} \mathrm{~B}$ NMR $\left(\mathrm{CDCl}_{3}\right): \delta 24.25$. 


\subsection{Preparation of Polymer 2 with Various Molecular Weights}

A 2-dram vial was charged with monomer $1(200 \mathrm{mg}, 1.2 \mathrm{mmol})$ and $2.4 \mathrm{~mL}$ DCM. The solution was stirred at $23^{\circ} \mathrm{C}$ for 5 minutes, after which a toluene solution of catalyst 3 was added to the solution ( $0.026 \mathrm{M}$ [Ni]; see Table S3 for amounts used). The resultant mixture was stirred at $23{ }^{\circ} \mathrm{C}$ for $1.5 \mathrm{~h}$ in the absence of light, after which the reaction was quenched via exposure to air. The mixture was concentrated to dryness, and the isolated polymer 2 was dried in a vacuum oven set to $100^{\circ} \mathrm{C}$ overnight. The yield was determined for each successful polymerization, and GPC data was acquired. Four molecular weights were targeted and conducted simultaneously in separate reactions (see Table S1). Recorded yields and GPC data are presented in Table S1, and GPC traces are provided in Figure S5.

Table S1: Representative Range of Molecular Weights Accessible

\begin{tabular}{ccccccc}
\hline Entry & $\begin{array}{c}\text { Volume of [3] } \\
\text { Solution }(\mathrm{mL})\end{array}$ & $\begin{array}{c}\text { Amount of } \\
{[\mathbf{N i}](\mathbf{m m o l})}\end{array}$ & \% Yield & $\begin{array}{c}\text { Target } \\
\boldsymbol{M}_{\boldsymbol{n}}(\mathrm{Da})\end{array}$ & $\begin{array}{c}\text { Actual } \\
\boldsymbol{M}_{\boldsymbol{n}}(\mathrm{Da})^{\mathbf{a}}\end{array}$ & $\boldsymbol{\Xi}^{\boldsymbol{b}}$ \\
\hline 1 & 0.38 & 0.010 & 79 & 20,000 & 24,070 & 1.42 \\
2 & 0.19 & 0.0050 & 87 & 40,000 & 44,290 & 1.42 \\
3 & 0.10 & 0.0025 & 74 & 80,000 & 83,860 & 1.49 \\
4 & 0.08 & 0.0020 & 69 & 100,000 & 130,800 & 1.70
\end{tabular}

${ }^{a}$ Determined by GPC with triple detection. ${ }^{b}$ Calculated from $M_{w} / M_{n}$.

\subsection{Preparation of High $M_{n}$ Polymer 2 under Dilute Conditions}

A 2-dram vial was charged with monomer 1 (500 mg, $3.0 \mathrm{mmol}$ ) and $30 \mathrm{~mL} \mathrm{DCM}(0.1 \mathrm{M})$. The solution was stirred at $23^{\circ} \mathrm{C}$ for 5 minutes, after which $0.19 \mathrm{~mL}$ of a toluene solution of catalyst 3 was added to the solution $\left(0.026 \mathrm{M}, 0.0049 \mathrm{mmol}\right.$ [Ni]; target $M_{n}=100,000$ Da). The resultant mixture was stirred at $23^{\circ} \mathrm{C}$ for $4 \mathrm{~h}$ in the absence of light, after which the reaction was quenched via exposure to air. The mixture was concentrated to dryness, and the isolated polymer 2 was dried in a vacuum oven set to $100^{\circ} \mathrm{C}$ overnight. Polymer 2 was collected as a colorless powder (447.6 mg, 90\% yield; 90,350 Da; 1.67 Đ). The GPC trace is provided in Figure S6. 


\subsection{Preparation of Low $M_{n}$ Polymer 2}

A 2-dram vial was charged with monomer $1(100 \mathrm{mg}, 0.6 \mathrm{mmol})$ and $1 \mathrm{~mL} \mathrm{DCM}$. The solution was stirred at $23^{\circ} \mathrm{C}$ for 5 minutes, after which a toluene solution of catalyst 3 was added to the solution $\left(0.18 \mathrm{M} ; 0.05 \mathrm{mmol}\right.$ [Ni]; target $\left.M_{n}=2,000 \mathrm{Da}\right)$. The resultant mixture was stirred at $23{ }^{\circ} \mathrm{C}$ for $1.5 \mathrm{~h}$ in the absence of light, after which the reaction was quenched via exposure to air. The mixture was concentrated to dryness, and the isolated polymer 2 was dried in a vacuum oven $\left(100^{\circ} \mathrm{C}\right)$ for $16 \mathrm{~h}$. Polymer 2 was collected as a colorless powder ( $447.6 \mathrm{mg}, 90 \%$ yield). GPC data is provided in Figure S7 $\left(M_{n}=4,865\right.$ $\mathrm{Da} ; 1.45 \mathrm{Ð}$ ), and the ${ }^{1} \mathrm{H}$ NMR spectrum used for end-group analysis is provided in Figure S25. ${ }^{3}$

\section{Determination of Living Character}

\subsection{Molecular Weight as a Function of Conversion}

A 2-dram vial was charged with monomer 1 (200 mg, $1.2 \mathrm{mmol})$, mesitylene (168 $\mu \mathrm{L}, 1.20$ mmol; used as an internal standard), and $4.7 \mathrm{~mL} \mathrm{CDCl} 3$. The solution was stirred at 23 ${ }^{\circ} \mathrm{C}$ for 5 minutes, after which $0.15 \mathrm{~mL}$ of a toluene solution of catalyst 3 was added to the solution $\left(0.026 \mathrm{M}, 0.0039 \mathrm{mmol}\left[\mathrm{Ni}\right.\right.$; t target $\left.M_{n}=50,000 \mathrm{Da}\right)$. The resultant mixture was stirred at $23^{\circ} \mathrm{C}$ in the absence of light. Aliquots $(0.2 \mathrm{~mL})$ of the reaction mixture were removed every 3 minutes for the first 30 minutes; subsequent aliquots were removed after 45 and 60 minutes of total reaction time. The aliquots were quenched by exposure to air, and analyzed using ${ }^{1} \mathrm{H}$ NMR spectroscopy. The samples were then concentrated to dryness and analyzed by GPC (see Table S2, Figures S1 and S11). The calculated $M_{n}$ data were plotted as a function of monomer conversion, which revealed a linear correlation (Figure 3). 
Table S2: Living Plot Molecular Weight and Conversion Data

\begin{tabular}{ccccc}
\hline Entry & $\begin{array}{c}\text { Reaction Time } \\
(\mathbf{m i n})\end{array}$ & \% Conversion & $\boldsymbol{M}_{\boldsymbol{n}}(\mathbf{D a})^{\boldsymbol{b}}$ & $\boldsymbol{\Xi}^{\mathbf{c}}$ \\
\hline 1 & 3 & 17 & 16,700 & 1.85 \\
2 & 6 & 40 & 26,670 & 2.25 \\
3 & 9 & 55 & 35,360 & 1.77 \\
4 & 12 & 68 & 40,570 & 1.83 \\
5 & 15 & 74 & 46,460 & 1.58 \\
6 & 18 & 79 & 49,840 & 1.62 \\
7 & 21 & 84 & 50,180 & 1.57 \\
8 & 24 & 88 & 51,640 & 1.50 \\
9 & 27 & 91 & 52,490 & 1.46 \\
10 & 30 & 93 & 54,570 & 1.54 \\
11 & 45 & 99 & 58,350 & 1.49 \\
12 & 60 & 100 & 60,200 & 1.47
\end{tabular}

${ }^{a}$ Product conversion determined based on ${ }^{1} \mathrm{H}$ NMR spectroscopy. ${ }^{b}$ Determined by GPC with triple detection. ${ }^{c}$ Calculated from $M_{w} / M_{n}$. 


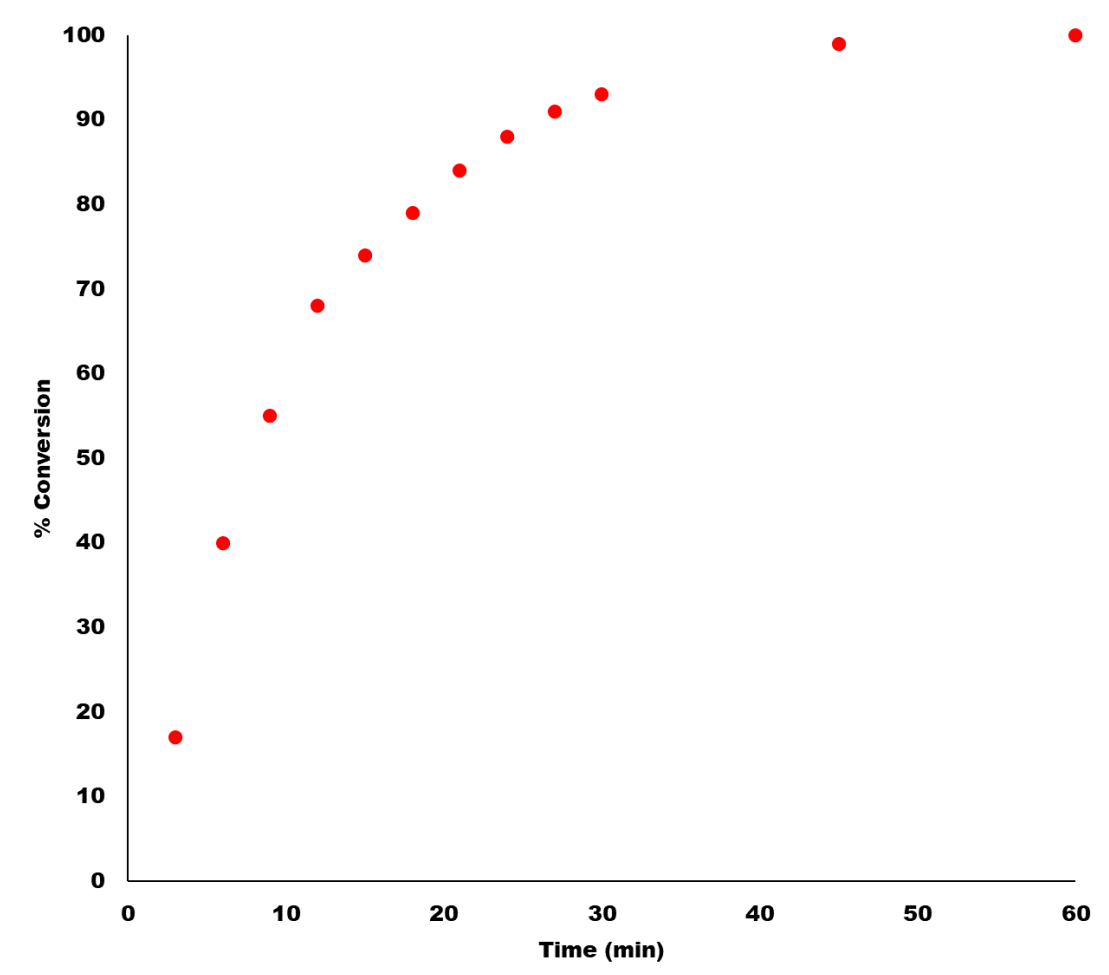

Figure S1: Percent conversion of monomer 1 as a function of time.

\subsection{Chain Extension Experiment}

A 2-dram vial was charged with monomer $1(200 \mathrm{mg}, 1.2 \mathrm{mmol})$ and $2.4 \mathrm{~mL} \mathrm{CDCl}$. The solution was stirred at $23^{\circ} \mathrm{C}$ for 5 minutes, after which $0.19 \mathrm{~mL}$ of a toluene solution of catalyst 3 was added to the solution $\left(0.026 \mathrm{M}, 0.0049 \mathrm{mmol}\right.$ [Ni]; target $\left.M_{n}=40,000 \mathrm{Da}\right)$. The resultant mixture was stirred at $23^{\circ} \mathrm{C}$ for $1.5 \mathrm{~h}$ in the absence of light. $\mathrm{A} 0.3 \mathrm{~mL}$ aliquot of the reaction mixture was removed and analyzed by ${ }^{1} \mathrm{H}$ NMR spectroscopy to confirm complete consumption of 1 . At this point, a $100 \mathrm{mg}(0.6 \mathrm{mmol})$ portion of 1 (in $0.2 \mathrm{~mL}$ $\mathrm{CDCl}_{3}$ ) was added to the polymerization mixture and allowed to stir. Another $0.3 \mathrm{~mL}$ aliquot was taken after $1.5 \mathrm{~h}$, and ${ }^{1} \mathrm{H}$ NMR spectral analysis revealed full consumption of the added 1 . A second $100 \mathrm{mg}(0.6 \mathrm{mmol}$ ) portion of 1 (in $0.2 \mathrm{~mL} \mathrm{CDCl}$ ) was added to the polymerization mixture and allowed to stir. Another $0.3 \mathrm{~mL}$ aliquot was taken after 1.5 $\mathrm{h}$, and ${ }^{1} \mathrm{H}$ NMR spectral analysis revealed full consumption of the added 1 . All NMR aliquots were concentrated under vacuum to dryness and analyzed by GPC (Table S3). For this experiment, we calculated mmol catalyst [Ni] removed in each aliquot and iteratively subtracted this from the original total $(0.0049 \mathrm{mmol}$ catalyst $)$. For each extension, we used this calculated mmol catalyst [Ni], the measured $M_{n}$ from the previous 
extension, and the amount of added monomer to determine target $M_{n}$. The observed data were consistent with successful chain extension (Figure 3).

Table S3: Molecular Weight Data for Chain Extension of Polymer 2

\begin{tabular}{ccccc}
\hline Entry & Extensions & $\boldsymbol{M}_{\boldsymbol{n}}(\mathrm{Da})^{\boldsymbol{a}}$ & ${\text { Target } \boldsymbol{M}_{\boldsymbol{n}}(\mathrm{Da})}$ & Polymer 2 $\boldsymbol{\Xi}^{\boldsymbol{b}}$ \\
\hline 1 & 0 & 40,160 & 40,000 & 1.40 \\
2 & 1 & 67,550 & 62,930 & 1.39 \\
3 & 2 & 93,910 & 94,115 & 1.42
\end{tabular}

${ }^{a}$ Determined by GPC with triple detection. ${ }^{b}$ Calculated from $M_{w} / M_{n}$.

\section{Block Copolymerizations with Additional Allenes}

The following sections detail the preparation of block copolymers incorporating monomer 1 and 1,2-butadiene or $\beta$-pinadiene. Full GPC data regarding molecular weights and dispersities germane to each polymerization and \% monomer incorporation relative to predicted amounts are provided in Table 2.

\subsection{Generation of Block Copolymer 6}

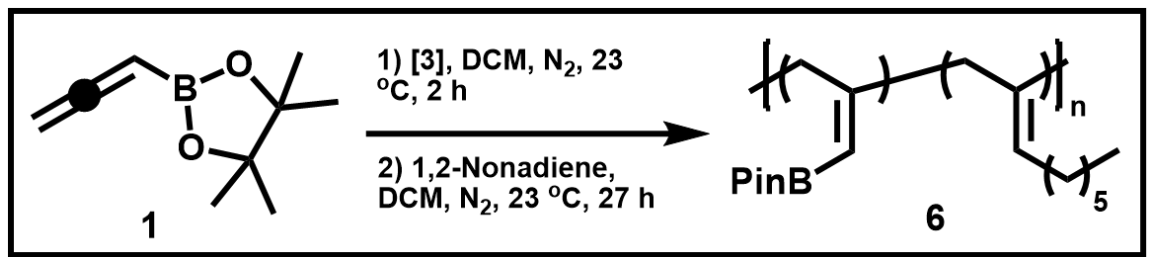

A 4-dram vial was charged with monomer 1 (300 mg, $1.8 \mathrm{mmol})$ and $9 \mathrm{~mL}$ DCM. The mixture was stirred at 23

${ }^{\circ} \mathrm{C}$ for 5 minutes, after which $0.23 \mathrm{~mL}$ of a toluene solution of catalyst 3 was added $(0.026$ M, $0.0060 \mathrm{mmol}$ [Ni]; target $M_{n}=100,000 \mathrm{Da}$ for final block copolymer; target $M_{n}=50,000$ Da per block). The resultant mixture was stirred at $23^{\circ} \mathrm{C}$ for $2 \mathrm{~h}$ in the absence of light. After the allotted reaction time, a $0.3 \mathrm{~mL}$ aliquot of the reaction mixture was removed and analyzed by NMR spectroscopy to confirm full conversion of monomer 1 . Afterwards, 1,2nonadiene ( $300 \mathrm{mg}, 2.4 \mathrm{mmol}$ ) in $0.3 \mathrm{~mL}$ DCM was added to the polymerization mixture. The reaction was stirred at $23{ }^{\circ} \mathrm{C}$ for $27 \mathrm{~h}$. After the allotted reaction time, the copolymerization was exposed to air, the mixture was concentrated to dryness, and the residue was dissolved in $4 \mathrm{~mL}$ THF. The THF solution was added dropwise to $16 \mathrm{~mL}$ $\mathrm{MeOH}$, resulting in the precipitation of a colorless solid. The solid was collected via centrifugation, and the material was reprecipitated a second time in the same manner 
previously described. After two precipitations, the collected solid was dried in a vacuum oven set to $100{ }^{\circ} \mathrm{C}$ overnight, yielding 6 as a colorless waxy solid $(275.2 \mathrm{mg}, 46 \%$ yield; $80,510 \mathrm{Da} ; 1.43 \mathrm{\Xi})$. The GPC traces for both blocks are provided in Figure 4, thermomechanical characterization is provided in Figure S14, and NMR spectral data were collected in $\mathrm{CDCl}_{3}$ (Figures S22-S24). ${ }^{1} \mathrm{H} \mathrm{NMR}\left(\mathrm{CDCl}_{3}\right)$ : $\delta 0.87(3 \mathrm{H}), 1.17(6.44 \mathrm{H})$, $1.25(8.41 \mathrm{H}), 1.93-2.03(1.75 \mathrm{H}), 2.50-2.72(1.85 \mathrm{H}), 3.15-3.34(0.83 \mathrm{H}), 5.22-5.26(1.38 \mathrm{H})$. ${ }^{13} \mathrm{C} \mathrm{NMR}\left(\mathrm{CDCl}_{3}\right): \delta 14.26,22.87,25.01,28.31,29.42,30.26,32.10,37.94,45.63,82.37$, 116.26, 127.11, 134.19, 161.96. ${ }^{11} \mathrm{~B}$ NMR $\left(\mathrm{CDCl}_{3}\right): \delta 25.54$.

\subsection{Generation of Block Copolymer 7}

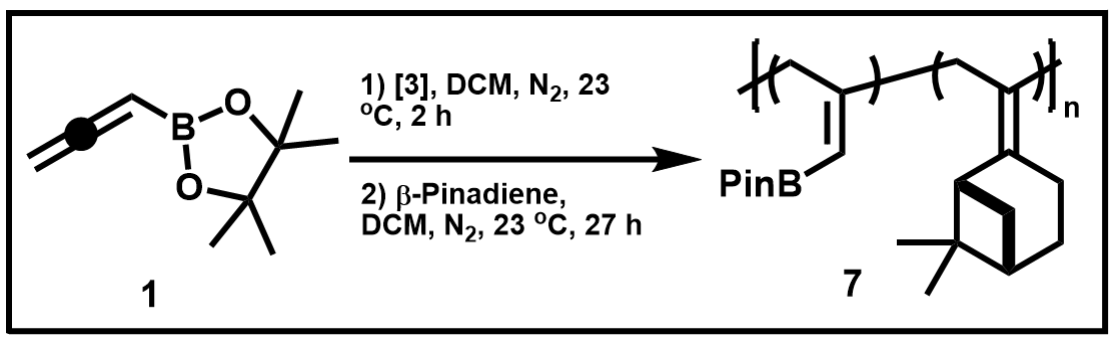

A 4-dram vial was charged with monomer 1 (300 $\mathrm{mg}$, $1.8 \mathrm{mmol}$ ) and $9 \mathrm{~mL} \mathrm{DCM}$. The mixture was stirred at $23^{\circ} \mathrm{C}$ for 5 minutes, after which $0.23 \mathrm{~mL}$ of a toluene solution of catalyst

3 was added $\left(0.026 \mathrm{M}, 0.0060 \mathrm{mmol}\right.$ [Ni]; target $M_{n}=100,000 \mathrm{Da}$ for final block copolymer; target $M_{n}=50,000$ Da per block). The resultant mixture was stirred at $23^{\circ} \mathrm{C}$ for $2 \mathrm{~h}$ in the absence of light. After the allotted reaction time, a $0.3 \mathrm{~mL}$ aliquot of the reaction mixture was removed and analyzed by NMR spectroscopy to confirm full conversion of monomer 1 . Afterwards, $\beta$-pinadiene $(300 \mathrm{mg}, 1.9 \mathrm{mmol})$ in $0.3 \mathrm{~mL} \mathrm{DCM}$ was added to the polymerization mixture. The reaction was stirred at $23^{\circ} \mathrm{C}$ for $27 \mathrm{~h}$. After the allotted reaction time, the copolymerization was exposed to air, the mixture was concentrated to dryness, and the residue was dissolved in $4 \mathrm{~mL}$ THF. The THF solution was added dropwise to $16 \mathrm{~mL} \mathrm{MeOH}$, resulting in the precipitation of a colorless solid. The solid was collected via centrifugation, and the material was reprecipitated a second time in the same manner previously described. After two precipitations, the collected solid was dried in a vacuum oven set to $100{ }^{\circ} \mathrm{C}$ overnight, yielding 7 as a colorless powder (424.5 mg, 71\% yield; $66,460 \mathrm{Da} ; 1.77$ Đ). The GPC traces for both blocks are provided in Figure 4, thermomechanical characterization is provided in Figures S15 and S16, and NMR spectral data were collected in $\mathrm{CDCl}_{3}$ (Figures S25-S27). ${ }^{1} \mathrm{H} \mathrm{NMR}\left(\mathrm{CDCl}_{3}\right): \delta 0.75$ $(3 \mathrm{H}), 1.17(12.20 \mathrm{H}), 1.84-1.90(2.97 \mathrm{H}), 2.26(3.02 \mathrm{H}), 2.58(1.01 \mathrm{H}), 2.95(1.10 \mathrm{H}), 3.15-$ $3.34(1.26 \mathrm{H}), 5.26(0.58 \mathrm{H}) .{ }^{13} \mathrm{C} \mathrm{NMR}\left(\mathrm{CDCl}_{3}\right): \delta 21.72,22.87,25.01,26.74,28.12,34.95$, 40.72, 46.37, 82.36, 116.17, 128.56, 136.47, 161.94. ${ }^{11} \mathrm{~B} \mathrm{NMR}\left(\mathrm{CDCl}_{3}\right): \delta 25.72$. 


\subsection{Replication Studies for Block Copolymerizations}

GPC data, isolated yield, and \%1 incorporation data for all materials in this section are provided in Table $\mathrm{S} 4$ at the end of this section.

\subsubsection{Borylated Allene 1 Polymerization Followed by Aliphatic Allene}

For Product 6: The protocol provided for accessing 6 in Section 4.1 was repeated exactly (except for switching solvent from DCM to toluene for solubility concerns) with the following changes in amounts of reagents employed: 1 (200 mg, $1.2 \mathrm{mmol}), 1,2-$ nonadiene (200 mg, $1.6 \mathrm{mmol}), 3\left(0.026 \mathrm{M}\right.$; $0.004 \mathrm{mmol}$ [Ni]; target $M_{n}=100,000 \mathrm{Da}$ for final block copolymer; target $M_{n}=50,000$ Da per block), and toluene (6 mL). After the block copolymer was isolated, the methanol filtrate was evaporated to dryness, which afforded a colorless solid that was determined to be homopolymer 2 by ${ }^{1} \mathrm{H}$ NMR spectroscopy. GPC characterization for the isolated sample of $\mathbf{6}$ is provided in Figure $\mathrm{S} 12$, and the ${ }^{1} \mathrm{H}$ NMR spectrum is provided in Figure S28. The combined yields of the block copolymer $6(197.0 \mathrm{mg})$ and the residual homopolymer $2(98.8 \mathrm{mg})$ total to 295.8 $\mathrm{mg}$, which amounts to $74 \%$ mass recovery.

For Product 7: The protocol provided for accessing 7 in Section 4.2 was repeated exactly (except for switching solvent from DCM to toluene for solubility concerns) with the following changes in amounts of reagents employed: 1 (250 mg, $1.5 \mathrm{mmol}), \beta$-pinadiene (250 mg, $1.6 \mathrm{mmol}), 3\left(0.026 \mathrm{M} ; 0.005 \mathrm{mmol}\right.$ [Ni]; target $M_{n}=100,000 \mathrm{Da}$ for final block copolymer; target $M_{n}=50,000$ Da per block), and toluene $(8 \mathrm{~mL})$. After the block copolymer was isolated, the methanol filtrate was evaporated to dryness, which afforded a colorless solid that was determined to be homopolymer 2 by ${ }^{1} \mathrm{H}$ NMR spectroscopy. GPC characterization for the isolated sample of 7 is provided in Figure S12, and the ${ }^{1} \mathrm{H}$ NMR spectrum is provided in Figure S29. The combined yields of block copolymer 7 $(297.2 \mathrm{mg})$ and the residual homopolymer $2(124.9 \mathrm{mg})$ total to $422.1 \mathrm{mg}$, which amounts to $84 \%$ mass recovery.

\subsubsection{Aliphatic Allene Polymerization Followed by Borylated Allene 1}

For Product 6: The protocol provided for accessing 6 in Section 4.1 was repeated (except for switching solvent from DCM to toluene for solubility concerns) while reversing the order monomer addition, and the following changes in amounts of reagents were employed: 1 (200 mg, $1.2 \mathrm{mmol}$ ), 1,2-nonadiene (200 mg, $1.6 \mathrm{mmol}), 3$ (0.026 M; 0.004 mmol [Ni]; target $M_{n}=100,000 \mathrm{Da}$ for final block copolymer; target $M_{n}=50,000$ Da per block), and toluene ( $6 \mathrm{~mL})$. After the block copolymer was isolated, the methanol filtrate was evaporated to dryness, which afforded a colorless solid that was determined to be 
homopolymer 2 by ${ }^{1} \mathrm{H}$ NMR spectroscopy. GPC characterization for the isolated sample of 6 is provided in Figure S13, and the ${ }^{1} \mathrm{H}$ NMR spectrum is provided in Figure S30. The combined yields of the block copolymer $6(180.4 \mathrm{mg})$ and the residual homopolymer 2 (101.6 mg) total to $282.0 \mathrm{mg}$, which amounts to $71 \%$ mass recovery.

For Product 7: The protocol provided for accessing 7 in Section 4.2 was repeated (except for switching solvent from DCM to toluene for solubility concerns) while reversing the order of addition of monomers, and the following changes in amounts of reagents were employed: 1 (250 mg, $1.5 \mathrm{mmol}$ ), $\beta$-pinadiene (250 mg, $1.6 \mathrm{mmol}), 3(0.026 \mathrm{M} ; 0.005$ mmol [Ni]; target $M_{n}=100,000 \mathrm{Da}$ for final block copolymer; target $M_{n}=50,000 \mathrm{Da}$ per block), and toluene $(8 \mathrm{~mL})$. After the block copolymer was isolated, the methanol filtrate was evaporated to dryness, which afforded a colorless solid that was determined to be homopolymer 2 by ${ }^{1} \mathrm{H}$ NMR spectroscopy. GPC characterization for the isolated sample of 7 is provided in Figure S13, and the ${ }^{1} \mathrm{H}$ NMR spectrum is provided in Figure S31. The combined yields of block copolymer $7(206.3 \mathrm{mg})$ and the residual homopolymer 2 (70.2 $\mathrm{mg}$ ) total to $276.5 \mathrm{mg}$, which amounts to $79 \%$ mass recovery.

Table S4: Tabulated Data for Block Copolymers from Replication Studies

\begin{tabular}{|c|c|c|c|c|c|c|c|}
\hline Product & $\begin{array}{c}\text { Initial } \\
M_{n}(\mathrm{Da})^{[\mathrm{a}]}\end{array}$ & $\begin{array}{c}\text { Initial } \\
\bigoplus^{[\mathrm{b}]}\end{array}$ & $\begin{array}{c}\text { Final } \\
M_{n}(\mathrm{Da})^{[\mathrm{a}]}\end{array}$ & $\begin{array}{r}\text { Final } \\
\bigoplus^{[b]}\end{array}$ & $\begin{array}{c}\text { Product Yield } \\
\text { (mg) }\end{array}$ & $\begin{array}{c}\% 1 \\
\text { Theo. }{ }^{[c]}\end{array}$ & $\begin{array}{c}\% 1 \\
\text { Actual }^{[\mathrm{d}]}\end{array}$ \\
\hline $6^{[\mathrm{e}]}$ & 60,610 & 1.54 & 137,650 & 1.53 & 197.0 & 43 & 27 \\
\hline $6^{[f]}$ & 16,800 & 2.34 & 65,800 & 1.60 & 180.4 & 43 & 20 \\
\hline $7^{[\mathrm{e}]}$ & 32,410 & 1.96 & 114,440 & 1.74 & 297.2 & 49 & 28 \\
\hline $7^{[f]}$ & 21,570 & 2.43 & 41,180 & 1.89 & 206.3 & 49 & 29 \\
\hline
\end{tabular}

See individual reaction conditions in Section 4.3 for amounts of monomers used. [a] Determined by GPC with triple. [b] Calculated from $M_{w} / M_{n}$. [c] Theoretical \% monomer 1 incorporation calculated from feed ratio. [d] Actual \% monomer 1 incorporation determined by ${ }^{1} \mathrm{H}$ NMR spectroscopy. [e] Products derived from initial polymerization of borylated allene 1. [f] Products derived from initial polymerization of aliphatic allene. 


\section{Post-Polymerization Modification}

\subsection{Suzuki-Miyaura Cross-Coupling of Polymer 2 with Phenyl Bromide ${ }^{7}$}

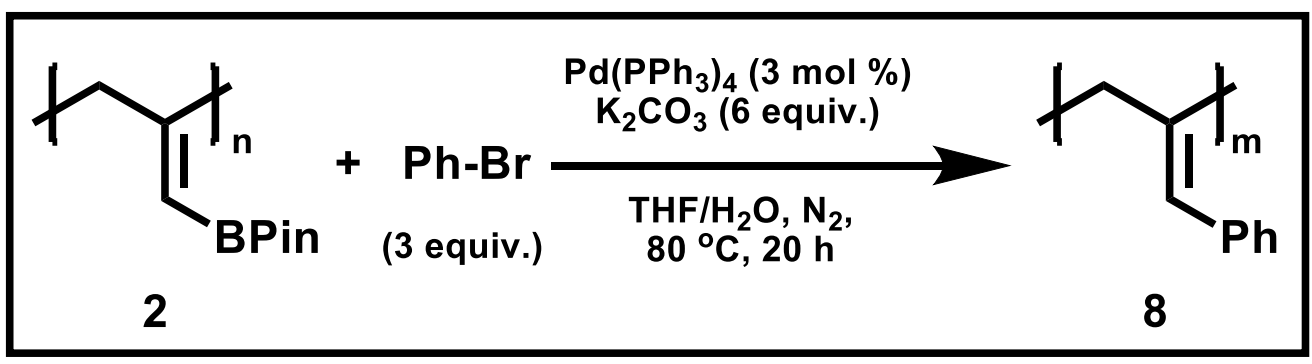

A 4-dram vial was charged with $\mathrm{Pd}\left(\mathrm{PPh}_{3}\right)_{4}$ (21 $\mathrm{mg}, 0.018$ $\mathrm{mmol}$ ) and 10 $\mathrm{mL}$ THF. The solution was added to a separate $20-\mathrm{mL}$ vial charged with polymer 2 (100 mg, $0.6 \mathrm{mmol} ; 61,410 \mathrm{Da}$; $1.87 \boxminus)$, and the mixture stirred until complete dissolution $\left([2]_{0}=0.06 \mathrm{M}\right)$. The mixture was added to a $50-\mathrm{mL}$ Schlenk flask, which was then placed under an active $\mathrm{N}_{2}$ atmosphere. Phenyl bromide $(0.19 \mathrm{~mL}, 1.8 \mathrm{mmol})$ was added to the THF mixture, followed by addition of an aqueous solution $(1.8 \mathrm{~mL}, 2.0 \mathrm{M})$ of $\mathrm{K}_{2} \mathrm{CO}_{3}(3.6 \mathrm{mmol})$. The mixture was degassed using four freeze-pump-thaw cycles, placed under a static $\mathrm{N}_{2}$ atmosphere, and heated to $80^{\circ} \mathrm{C}$ for $20 \mathrm{~h}$ in the absence of light. The water layer was removed from the biphasic mixture, and the THF solution was concentrated to $\sim 2 \mathrm{~mL}$ under reduced pressure. Dropwise addition of the THF solution to rapidly stirring $\mathrm{MeOH}$ $(18 \mathrm{~mL})$ precipitated the coupled product, 8 . The $\mathrm{MeOH}$ suspension was centrifuged and decanted, and the isolated polymer was dissolved in THF ( $2 \mathrm{~mL}) .8$ was precipitated three times, dissolved in THF, and concentrated to dryness under reduced pressure in a tared 4-dram vial, yielding 8 as a yellow solid ( $64.8 \mathrm{mg}, 93 \%$ yield). ${ }^{1} \mathrm{H}$ NMR analysis revealed formation of 8 with $96 \%$ conversion (Figure S20; compared product arene resonance integration to residual BPin of starting material), and GPC analysis of 8 revealed a unimodal distribution of a polymer that possessed material properties consistent with a well-controlled post-synthetic modification $\left(M_{n}[8]=52,000 \mathrm{Da}, 1.86 \boxminus\right.$; Figure 5). Lastly, both ${ }^{1} \mathrm{H}$ and ${ }^{13} \mathrm{C}$ NMR spectral analyses of product 8 were consistent with a literature report on polyphenylallene ${ }^{5}$ (some minor, unidentified impurities present; Figures S32 and S33). ${ }^{1} \mathrm{H}$ NMR $\left(\mathrm{CDCl}_{3}\right): \delta 2.96(2 \mathrm{H}), 6.35(1 \mathrm{H}), 6.95-7.20(5.76 \mathrm{H}) .{ }^{13} \mathrm{C} \mathrm{NMR}\left(\mathrm{CDCl}_{3}\right): \delta$ $39.27,126.35,128.10,128.64,137.21,137.77$.

\section{Material Characterization}

All thermal characterization was performed with as-precipitated, and subsequently dried, products.

The thermal stability of polymer 2 was evaluated by TGA analysis, and a thermal decomposition onset at $255^{\circ} \mathrm{C}$ was observed (Figure S8; heating rate $=10^{\circ} \mathrm{C} \mathrm{min}-1$ under $\mathrm{N}_{2}$ ). While a film of polymer 2 could be cast from $\mathrm{CHCl}_{3}(5 \mathrm{wt}$. \% polymer), the films were 
brittle and could not be analyzed with a film tension clamp. Powder DMA of polymer 2 was conducted from 100 to $250^{\circ} \mathrm{C}\left(0.5 \mathrm{~Hz}\right.$; heating rate $\left.=2^{\circ} \mathrm{C} \mathrm{min}-1\right)$, and the temperature value at Tan $\delta_{\text {MAX }}$ was $147^{\circ} \mathrm{C}$ (Figure S9). DSC of polymer 2 was conducted starting from $-70{ }^{\circ} \mathrm{C}$ and heating to $200^{\circ} \mathrm{C}$, followed by cooling the sample to $-70^{\circ} \mathrm{C}$, then heating the sample back to $200^{\circ} \mathrm{C}$ (heating and cooling rates $=10^{\circ} \mathrm{C} \mathrm{min}-1$ ). The DSC thermogram provided in Figure $\mathrm{S} 10$ is of the last heating cycle, as no thermal events were recorded in the cooling cycle. The recorded $T_{g}$ for 2 was measured at $148^{\circ} \mathrm{C}$.

Similar TGA analyses were conducted for products 6 and 7 , and the observed thermal decompositions are as follow: $6\left(331{ }^{\circ} \mathrm{C}\right.$, Figure S14); 7 (273 ${ }^{\circ} \mathrm{C}$, Figure S15). TGA analysis was also conducted for each material with a slower heating rate $\left(5^{\circ} \mathrm{C} \mathrm{min}{ }^{-1}\right)$, and the recorded thermograms confirmed only one $T_{D}$ was observable for each specimen.

Efforts toward casting films of block copolymers $\mathbf{6}$ and $\mathbf{7}$ were successful when employing $\mathrm{CHCl}_{3}$ as the solvent of choice ( $5 \mathrm{wt}$. \% polymer). Unfortunately, the as-casted films could not be mounted and tested. As such, powder DMA was employed for discerning thermal transitions. Since 6 was a waxy solid and not easily handled for powder experiments, product 7 was solely evaluated by DMA analysis. Powder DMA analysis of 7 was conducted from 30 to $250{ }^{\circ} \mathrm{C}\left(1 \mathrm{~Hz}\right.$, heating rate $\left.=2{ }^{\circ} \mathrm{C} \mathrm{min}-1\right)$, and the temperature value at Tan $\delta_{\text {MAX }}$ was observed at $161^{\circ} \mathrm{C}$ (Figure S16).

\subsection{GPC Traces and Thermomechanical Data of Polymer 2}

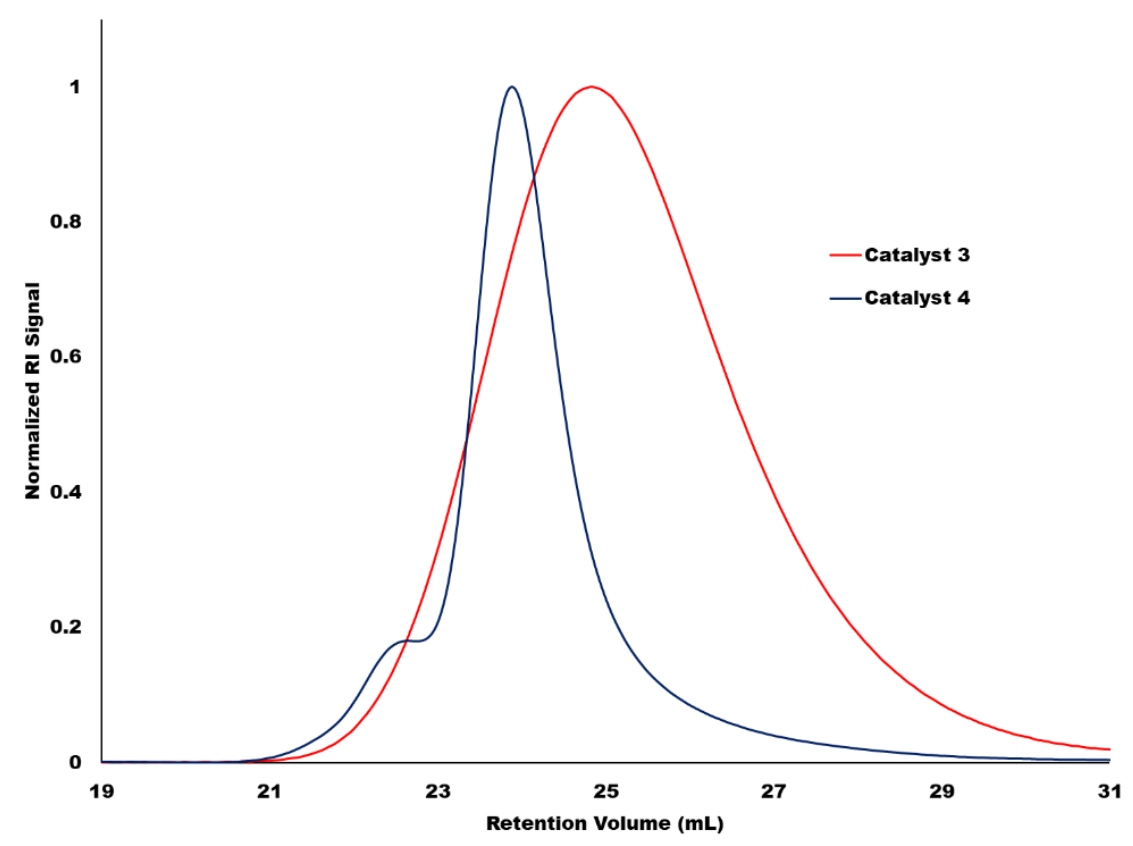

Figure S2: GPC Traces of Polymer 2 from Catalyst Screen 


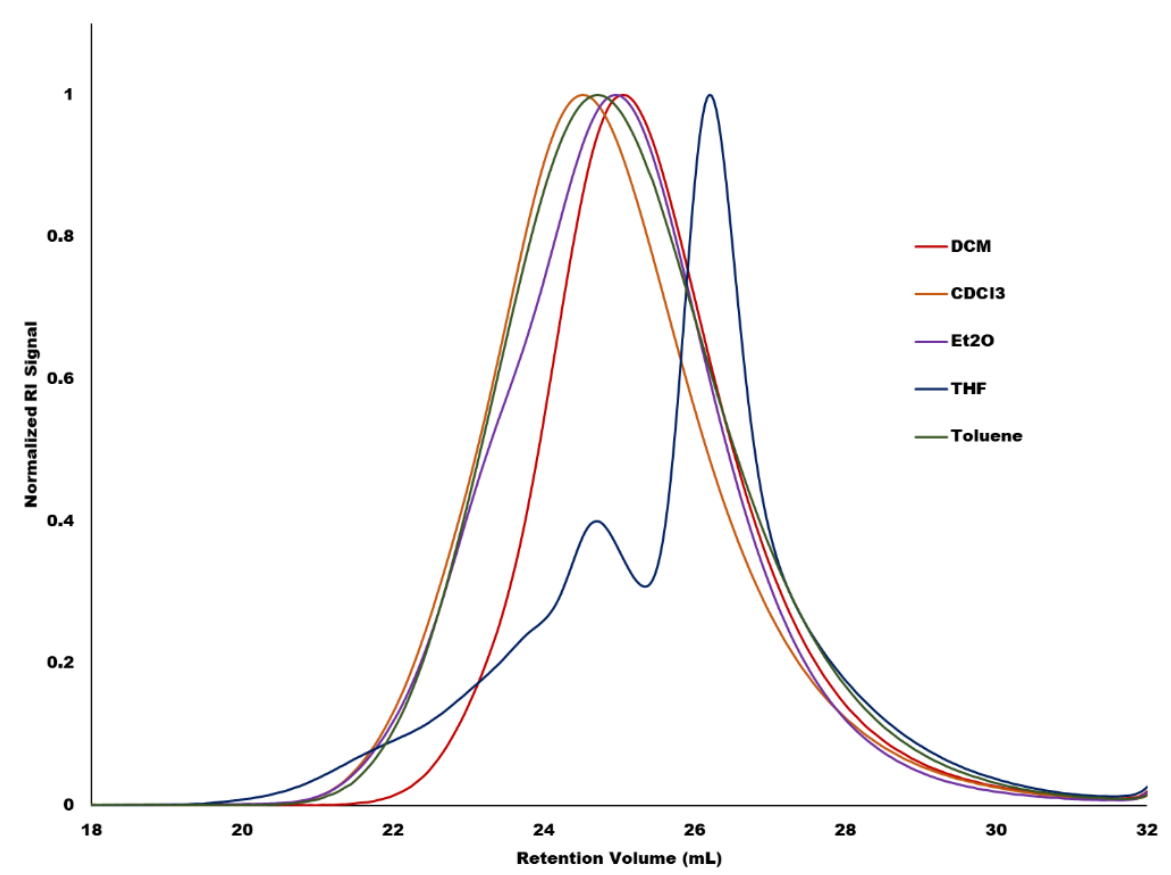

Figure S3: GPC Traces of Polymer 2 from Solvent Screen

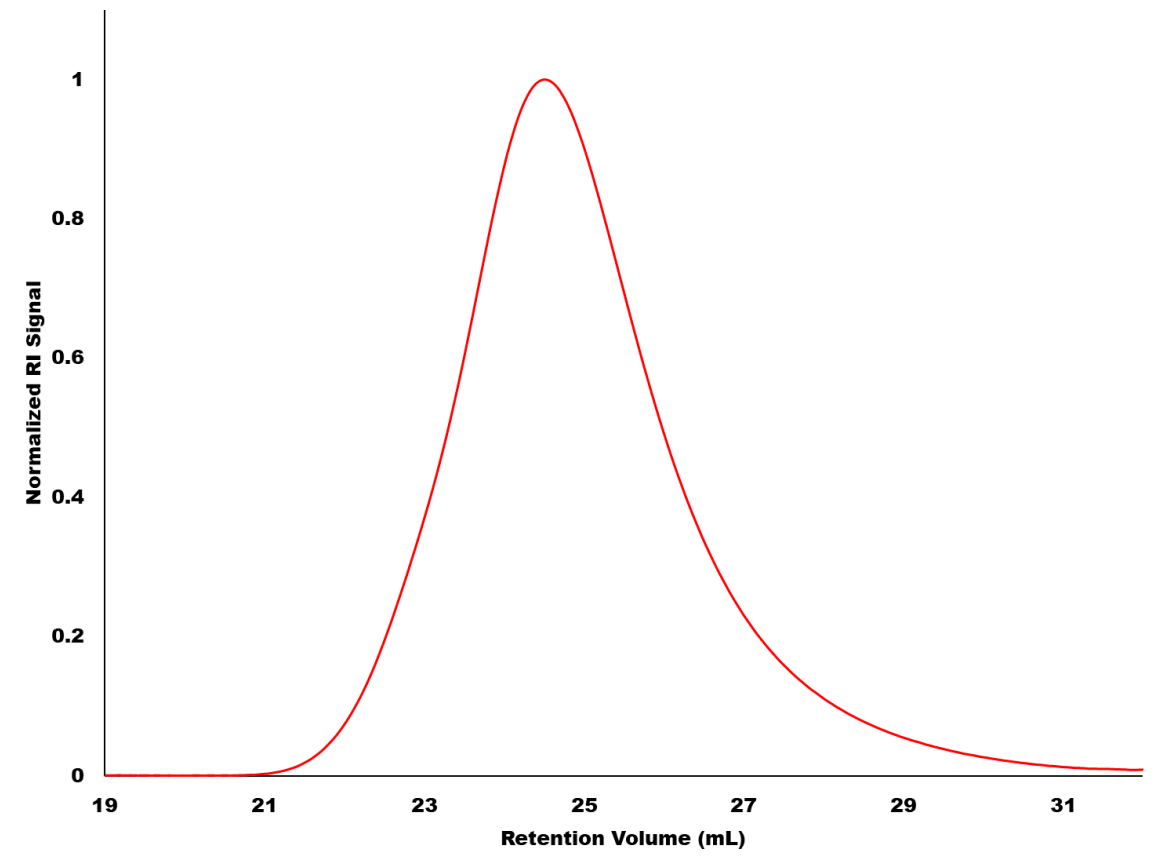

Figure S4: GPC Trace of Scale-Up of Polymer 2 


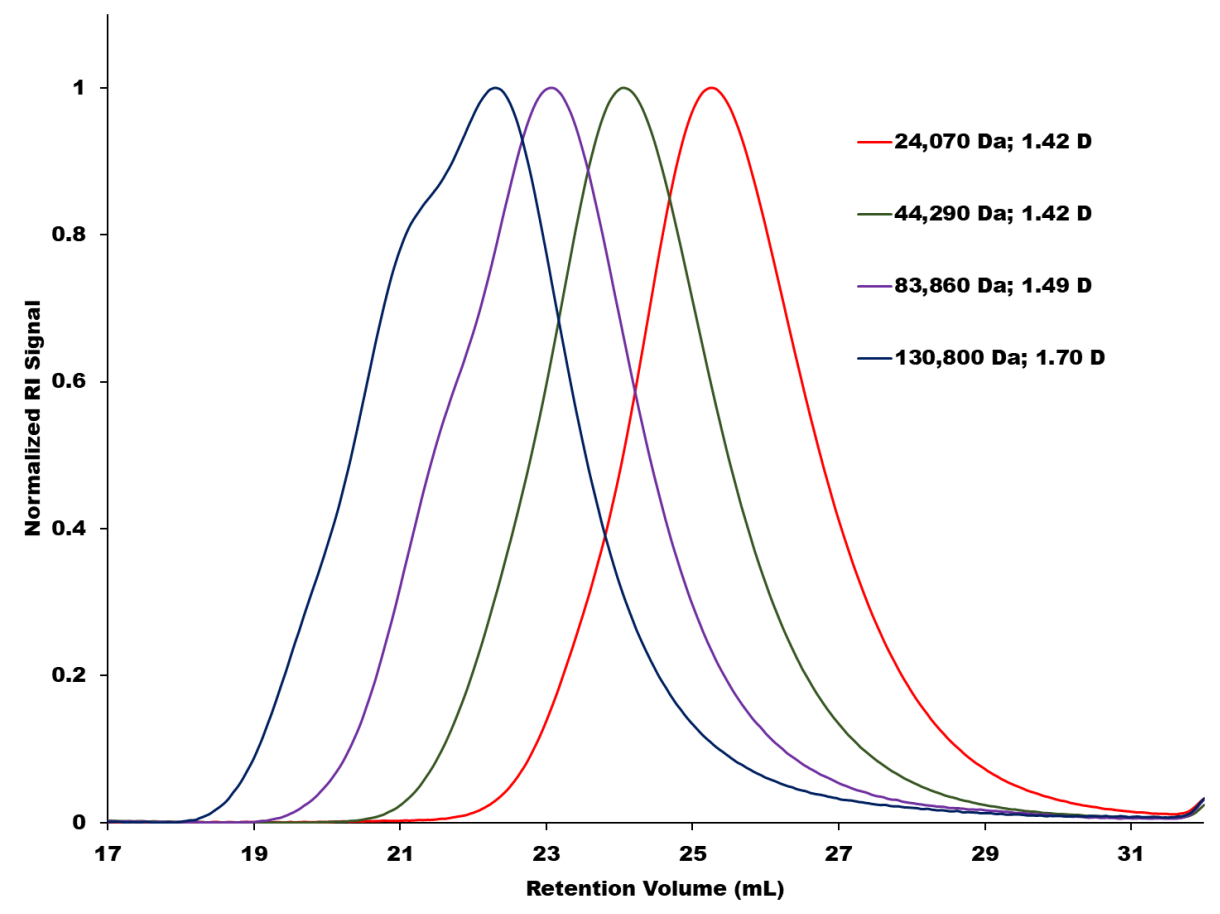

Figure S5: GPC Traces for Representative Molecular Weights of Polymer 2

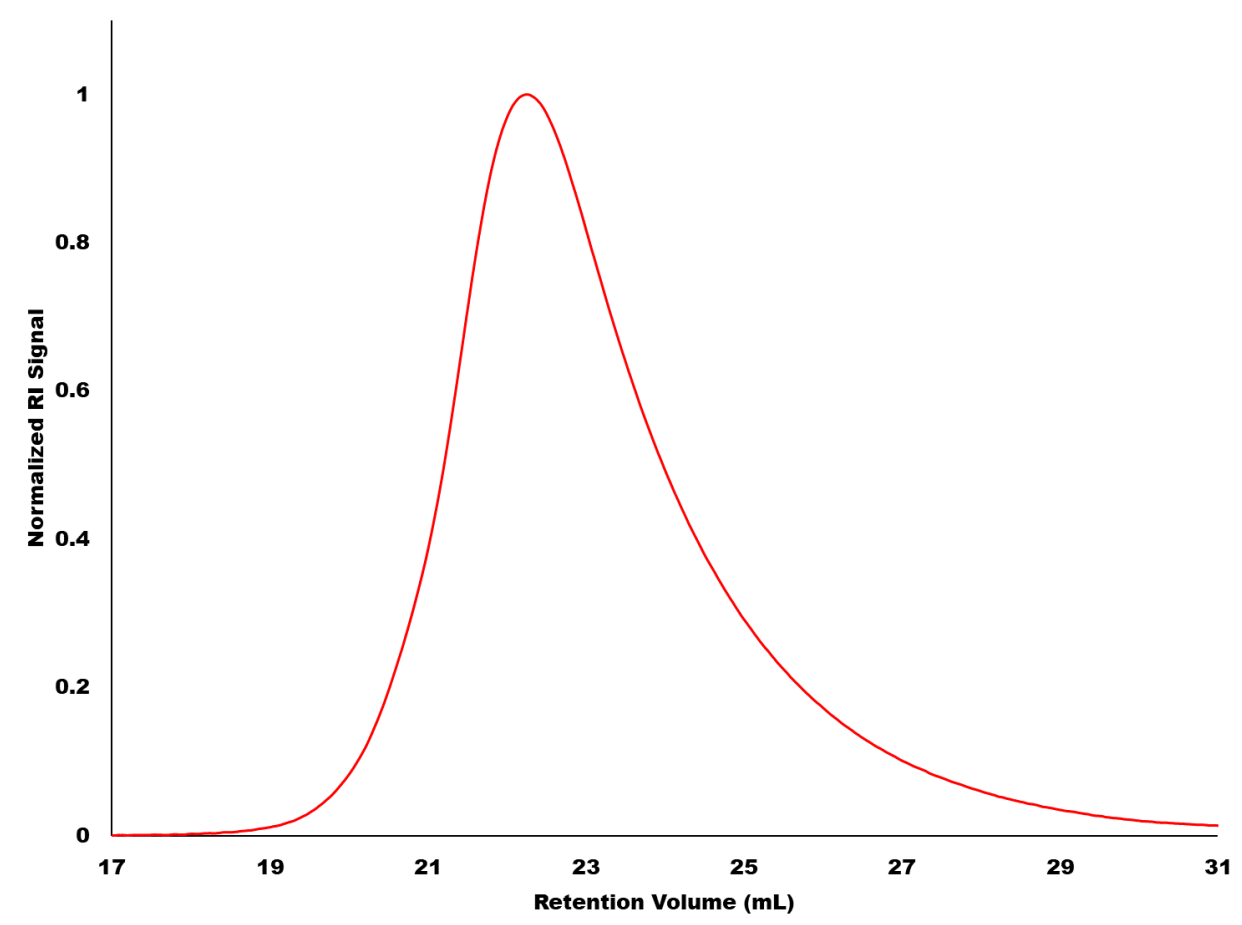

Figure S6: GPC Trace of Dilute Polymerization of Polymer 2 


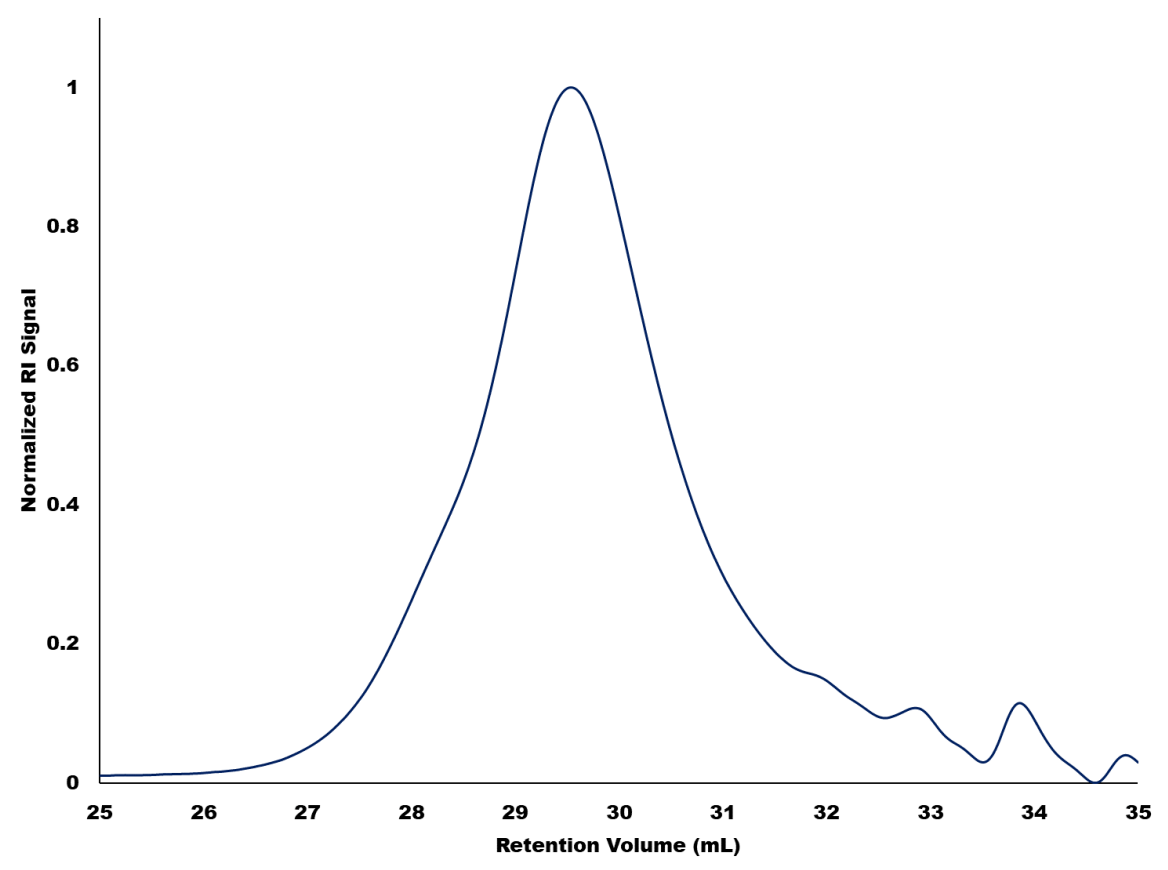

Figure S7: GPC Trace of Low $M_{n}$ Polymer 2

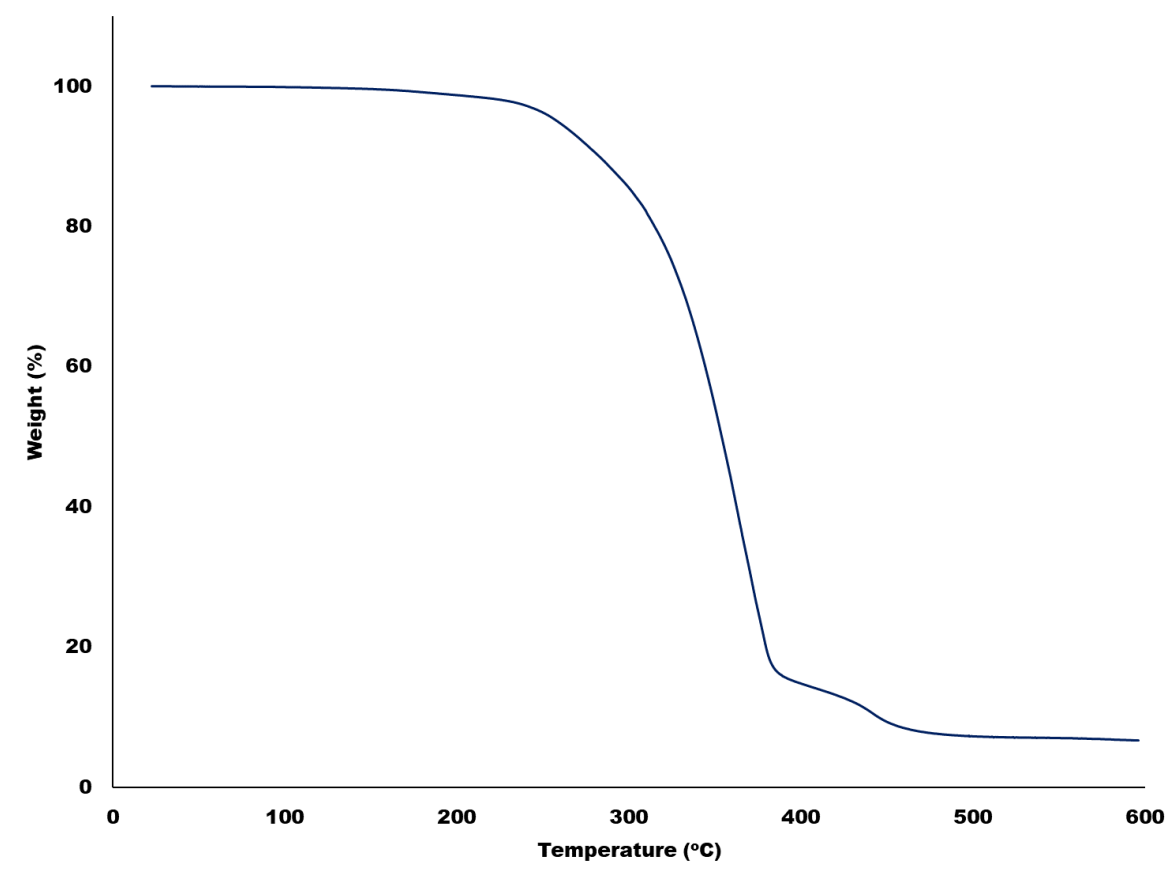

Figure S8: TGA Thermogram of Polymer $2\left(10^{\circ} \mathrm{C} \mathrm{min}-1\right)$ 


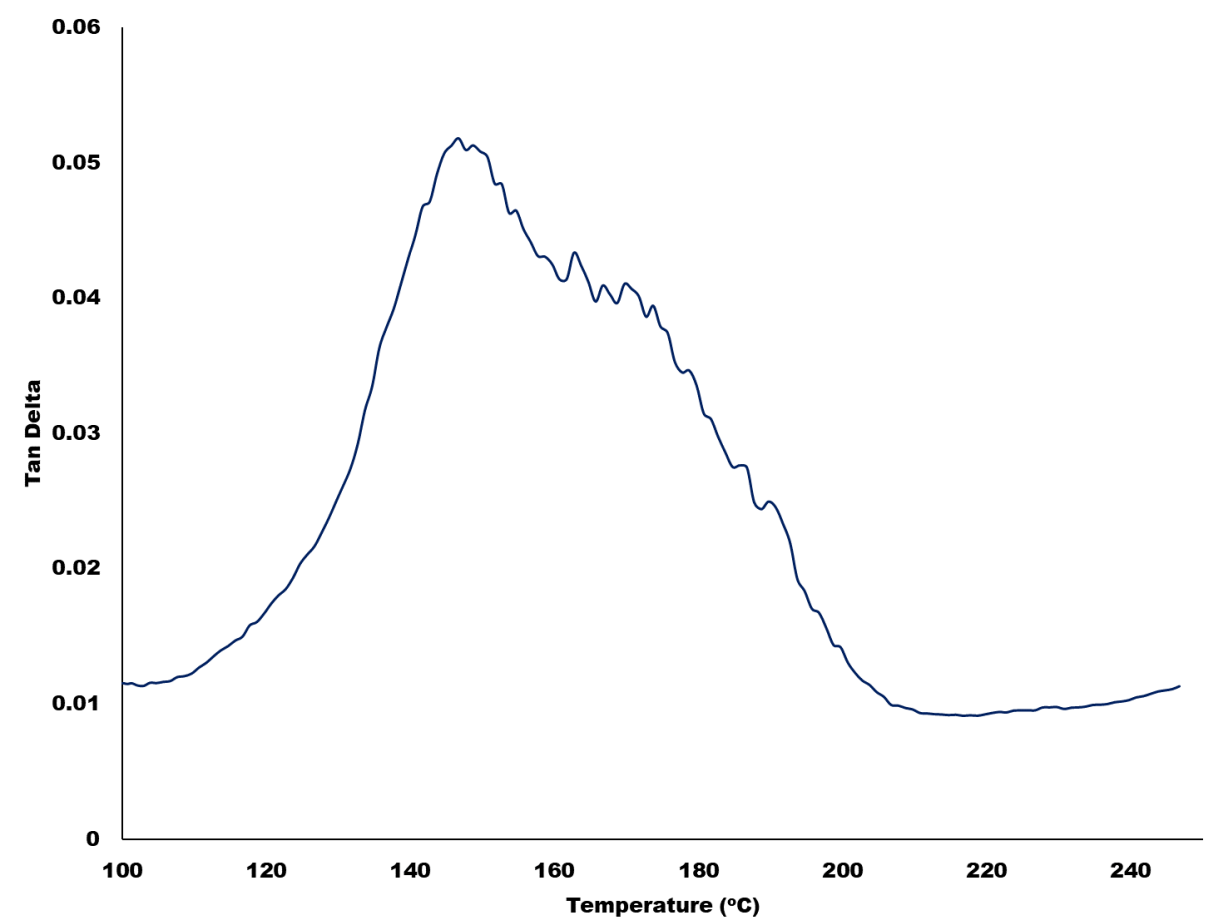

Figure S9: Powder DMA Thermogram of Polymer $2\left(0.5 \mathrm{~Hz}, 2^{\circ} \mathrm{C} \mathrm{min}{ }^{-1}\right)$

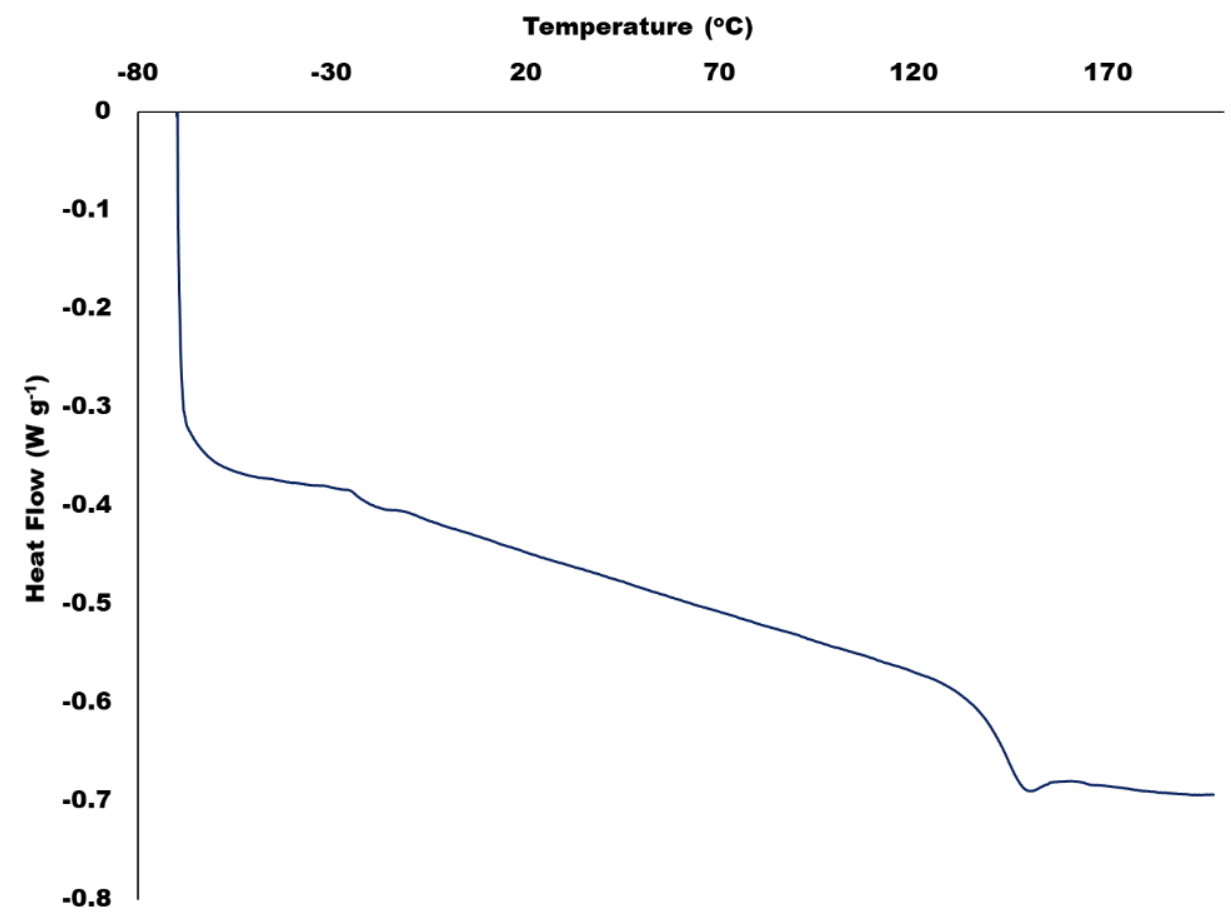

Figure S10: DSC Thermogram of Polymer $2\left(10^{\circ} \mathrm{C} \mathrm{min}-1\right.$ heating rate) 


\subsection{GPC Traces for Living Character Experiments}

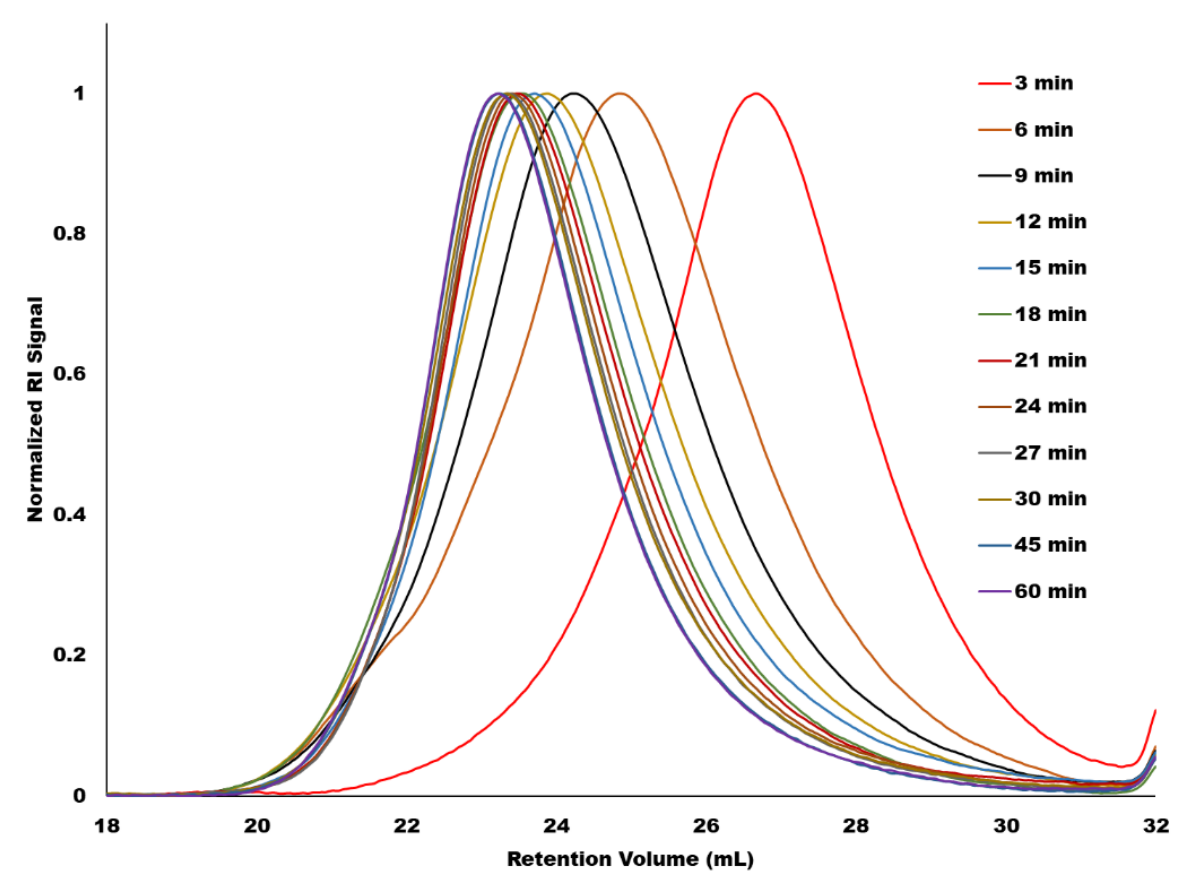

Figure S11: GPC Traces of Living Experiment

\subsection{GPC Traces and Thermomechanical Data of Block Copolymers}

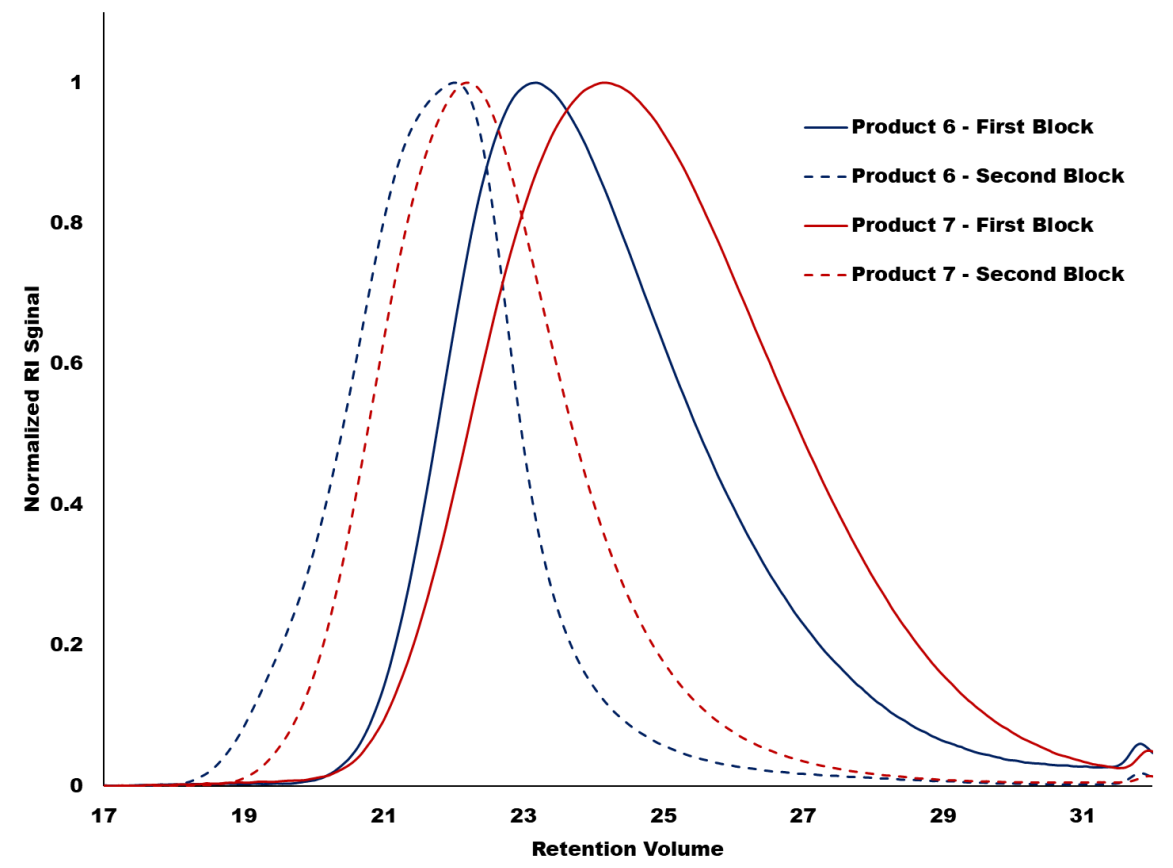

Figure S12: GPC Traces of Block Copolymerization Replications 


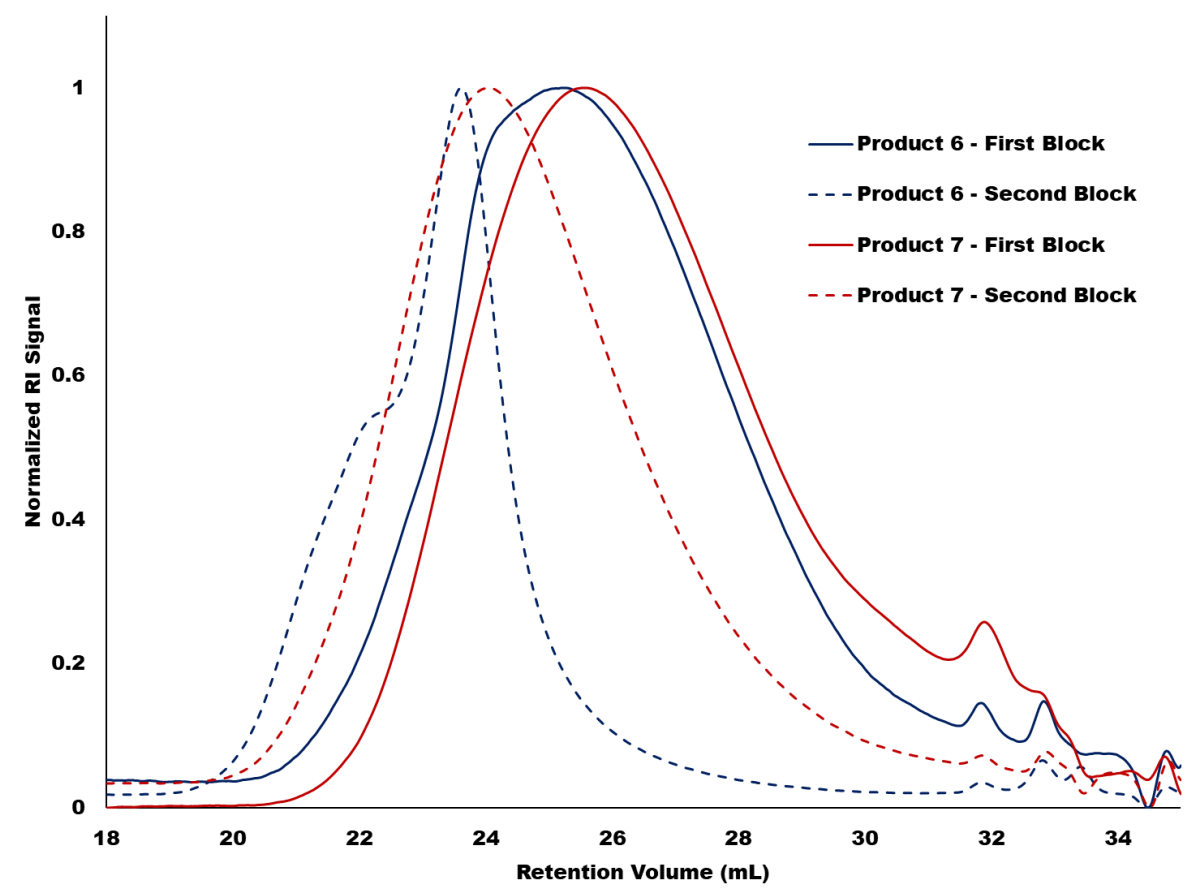

Figure S13: GPC Traces Block Copolymerizations with Reversed Monomer Addition

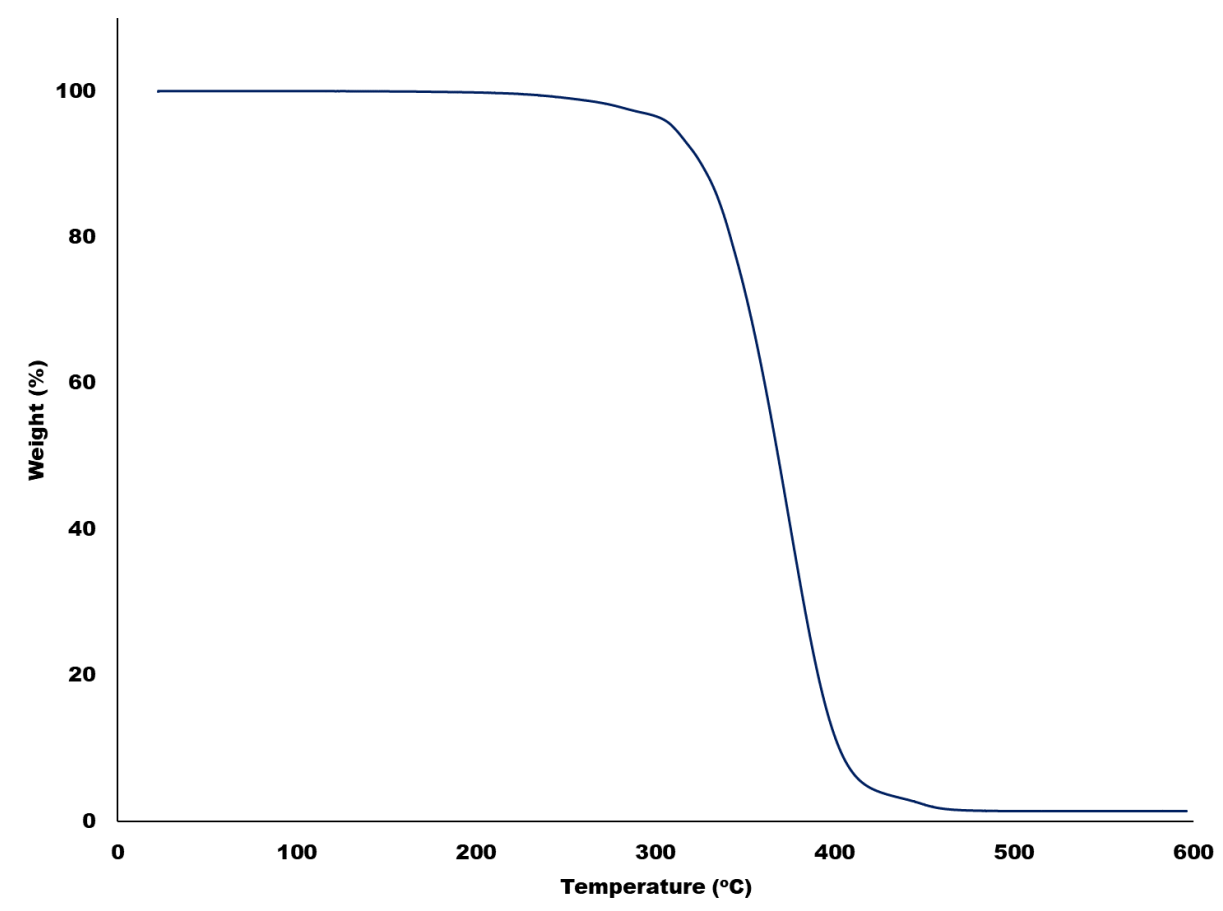

Figure S14: TGA Thermogram of Block Copolymer $6\left(10^{\circ} \mathrm{C}\right.$ min $\left.^{-1}\right)$ 


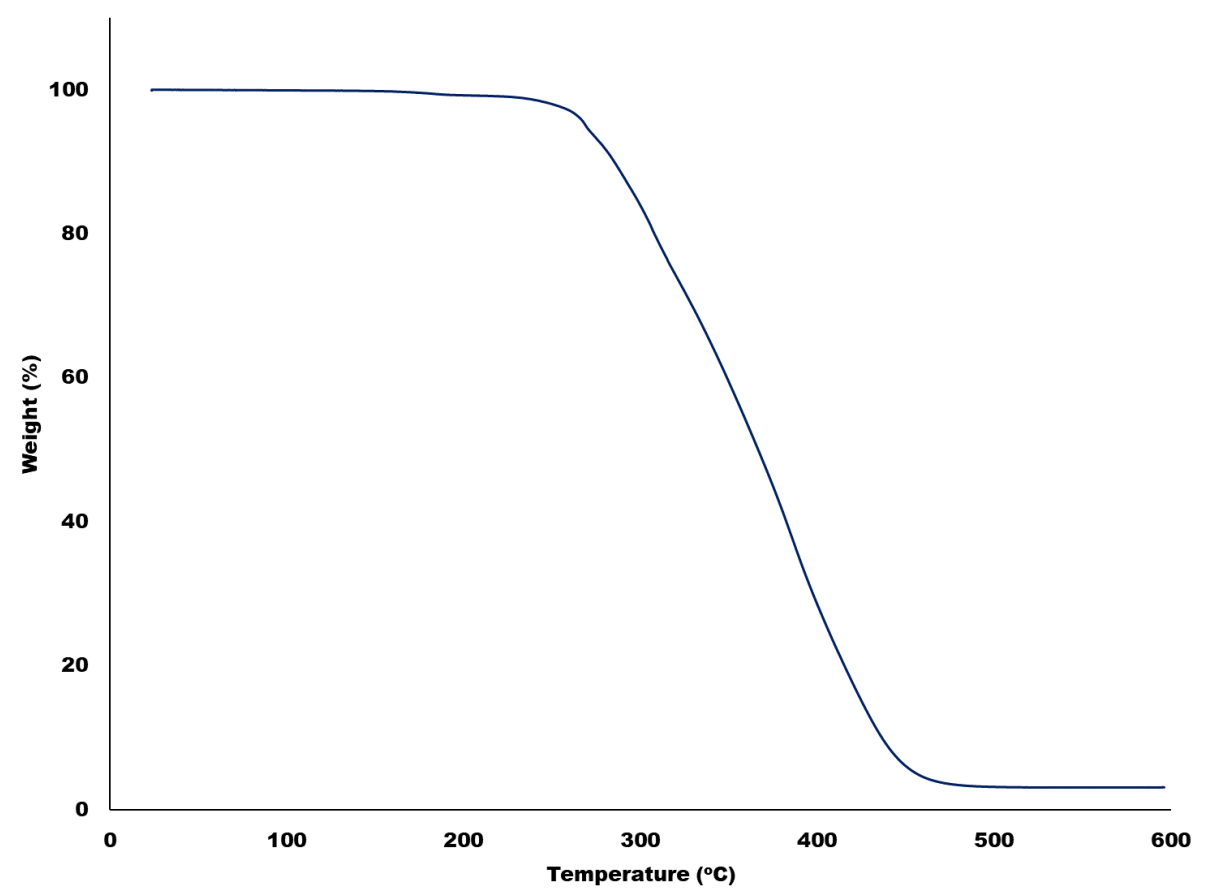

Figure S15: TGA Thermogram of Block Copolymer $7\left(10^{\circ} \mathrm{C}\right.$ min $\left.^{-1}\right)$

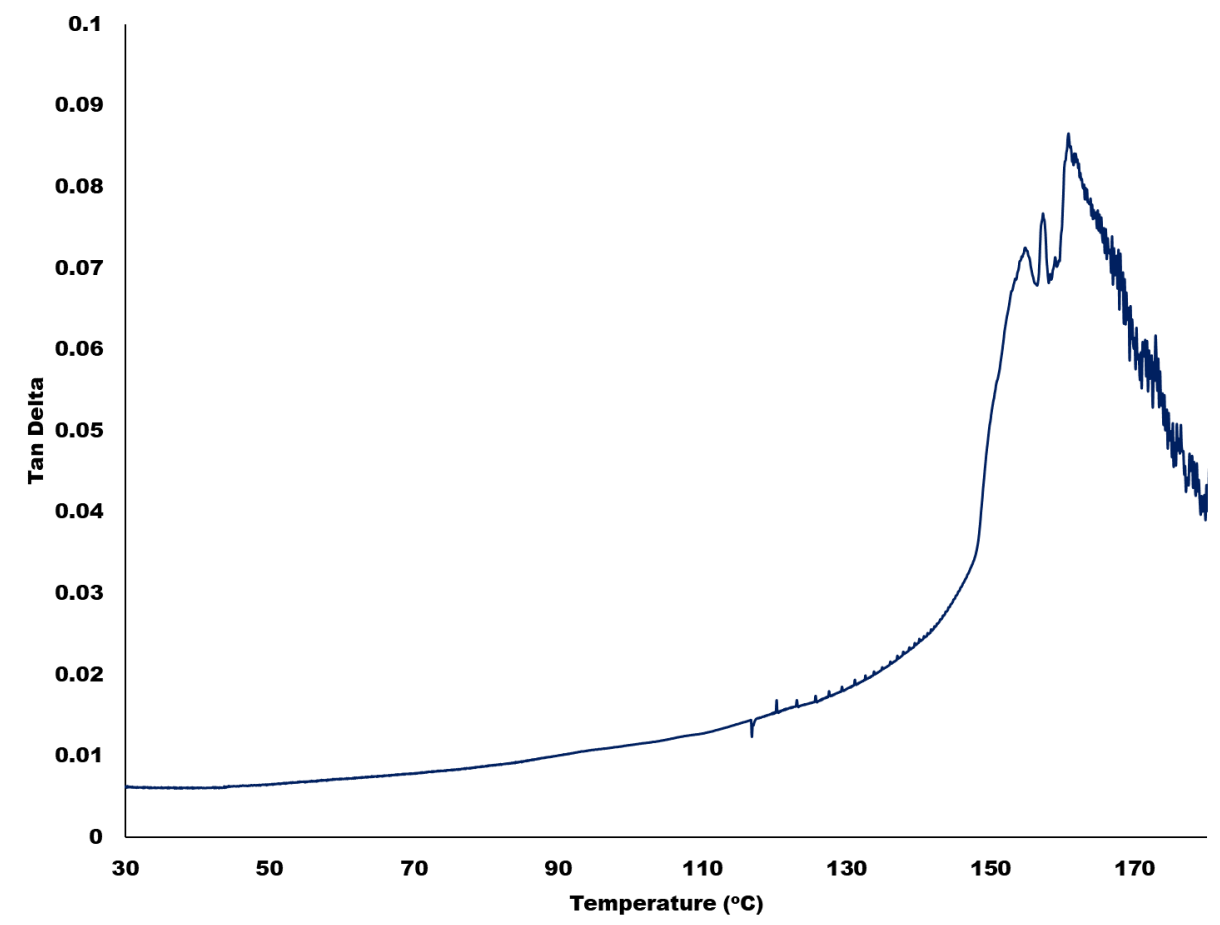

Figure S16: Powder DMA Thermogram of $7\left(1 \mathrm{~Hz}, 2^{\circ} \mathrm{C} \min ^{-1}\right)$ 


\section{NMR Spectroscopic Data}
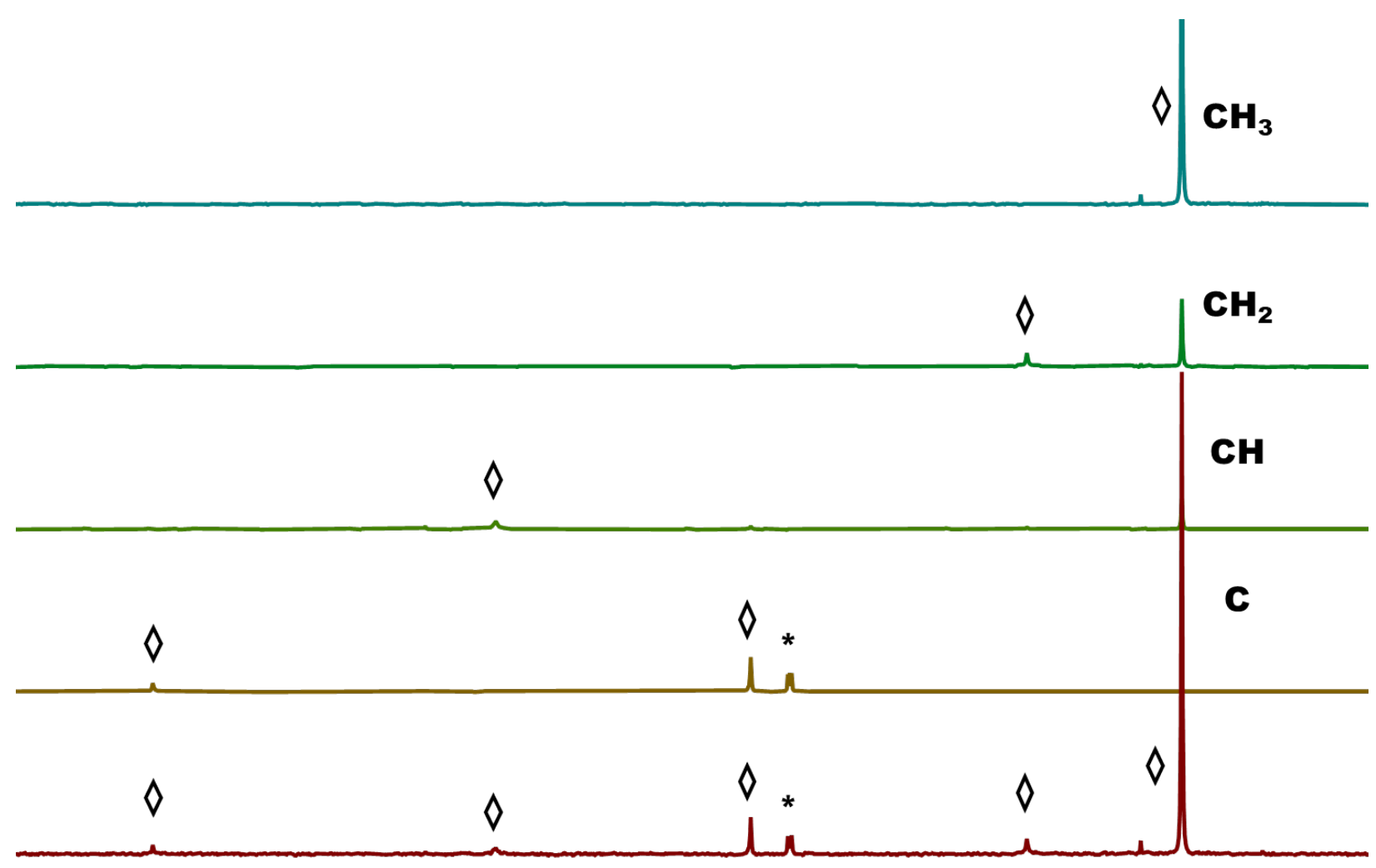

80

$80 \quad 170$
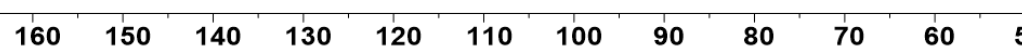

$\boldsymbol{\delta}$

Figure S17: DEPTQ NMR Spectra of Polymer 2 in $\mathrm{CDCl}_{3} .\left(^{*}\right)$ designates the solvent peak, $(\diamond)$ designates polymer resonances observed in each trace. The $\mathrm{CH}_{3}$ resonance is observed in multiple spectra due to incomplete suppression of this resonance. 


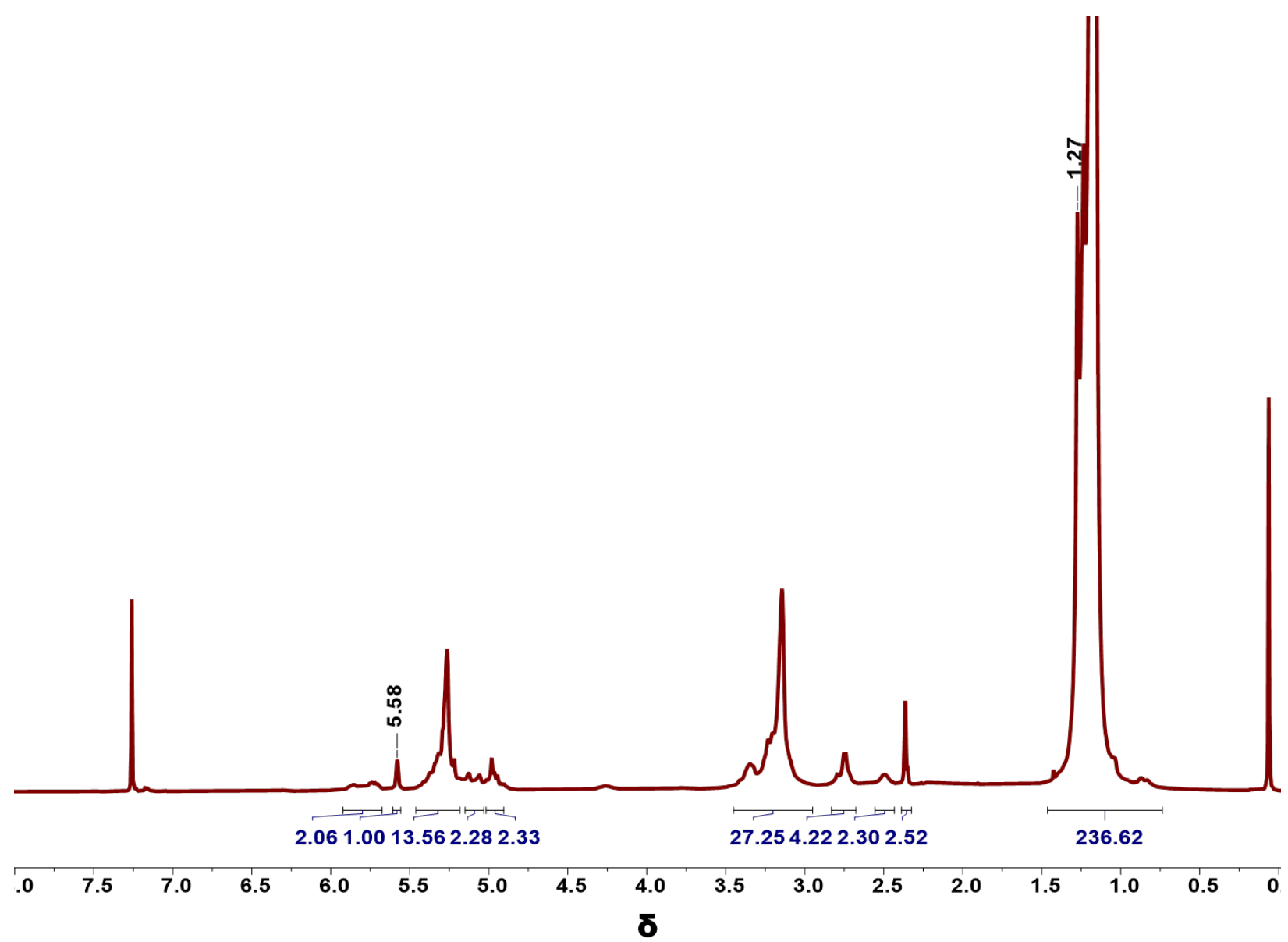

Figure S18: ${ }^{1} \mathrm{H}$ NMR Spectrum of Low $M_{n}$ Polymer 2 in $\mathrm{CDCl}_{3}$. Annotated peaks were used for calculating the molecular weight of $2 .{ }^{6}$ 


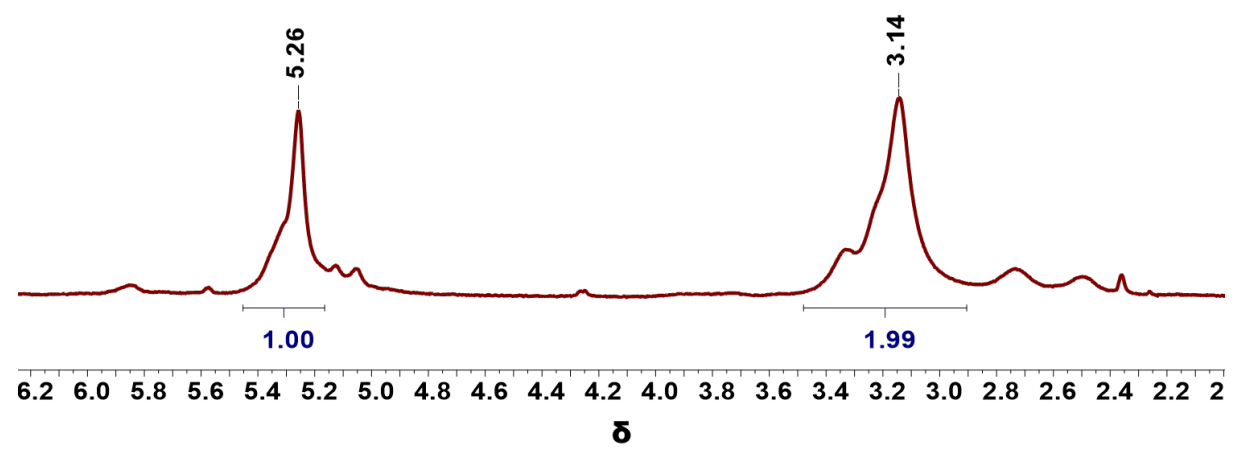

Figure S19: Magnified ${ }^{1} \mathrm{H}$ NMR Spectrum of Polymer 2 in $\mathrm{CDCl}_{3}$ with Integrations of Major Resonances

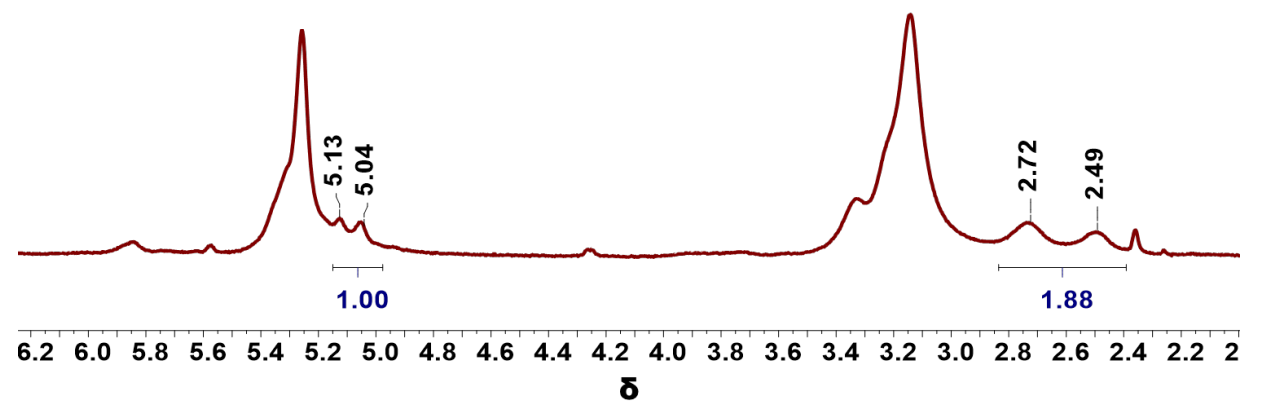

Figure S20: Magnified ${ }^{1} \mathrm{H}$ NMR Spectrum of Polymer 2 in $\mathrm{CDCl}_{3}$ with Integrations of Minor Resonances 


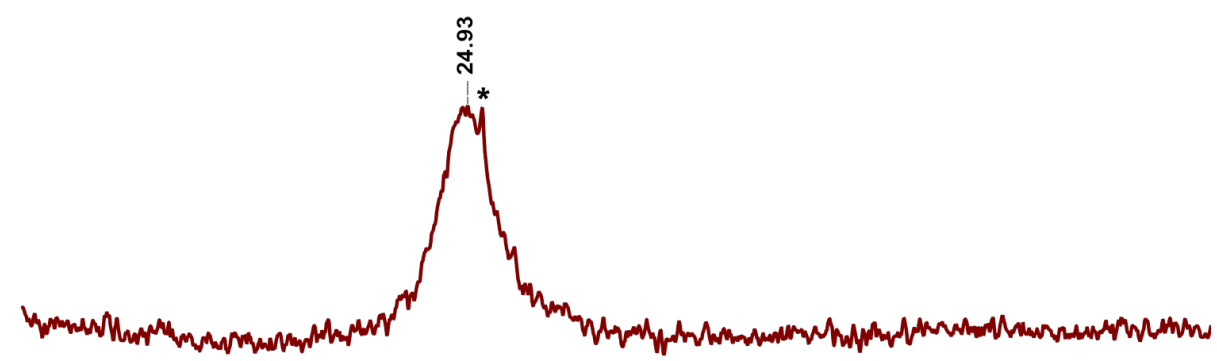

Figure S21: ${ }^{11} \mathrm{~B}$ NMR Spectrum of Polymer 2 in $\mathrm{CDCl}_{3} .\left(^{*}\right)$ denotes residual monomer 1.

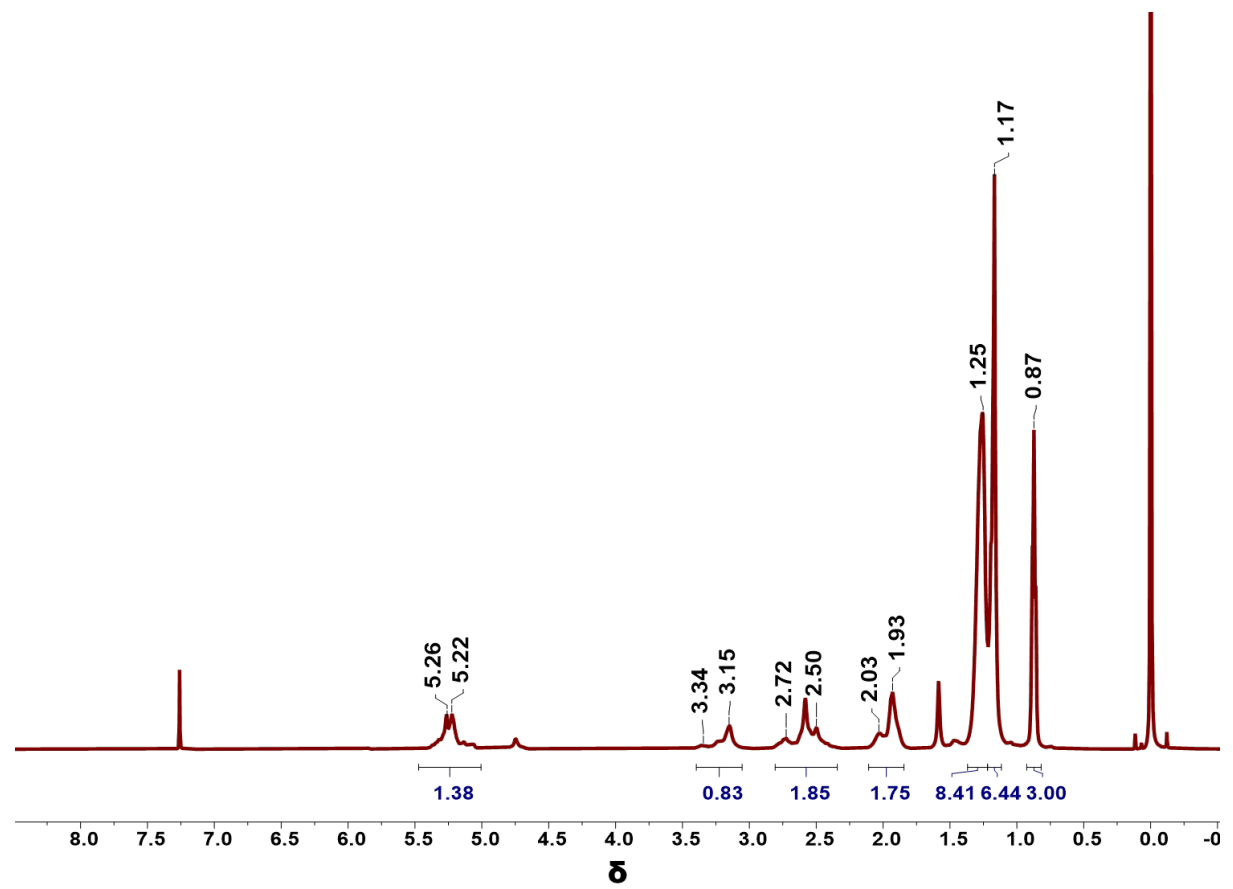

Figure S22: ${ }^{1} \mathrm{H}$ NMR Spectrum of Block Copolymer 6 in $\mathrm{CDCl}_{3}$ 


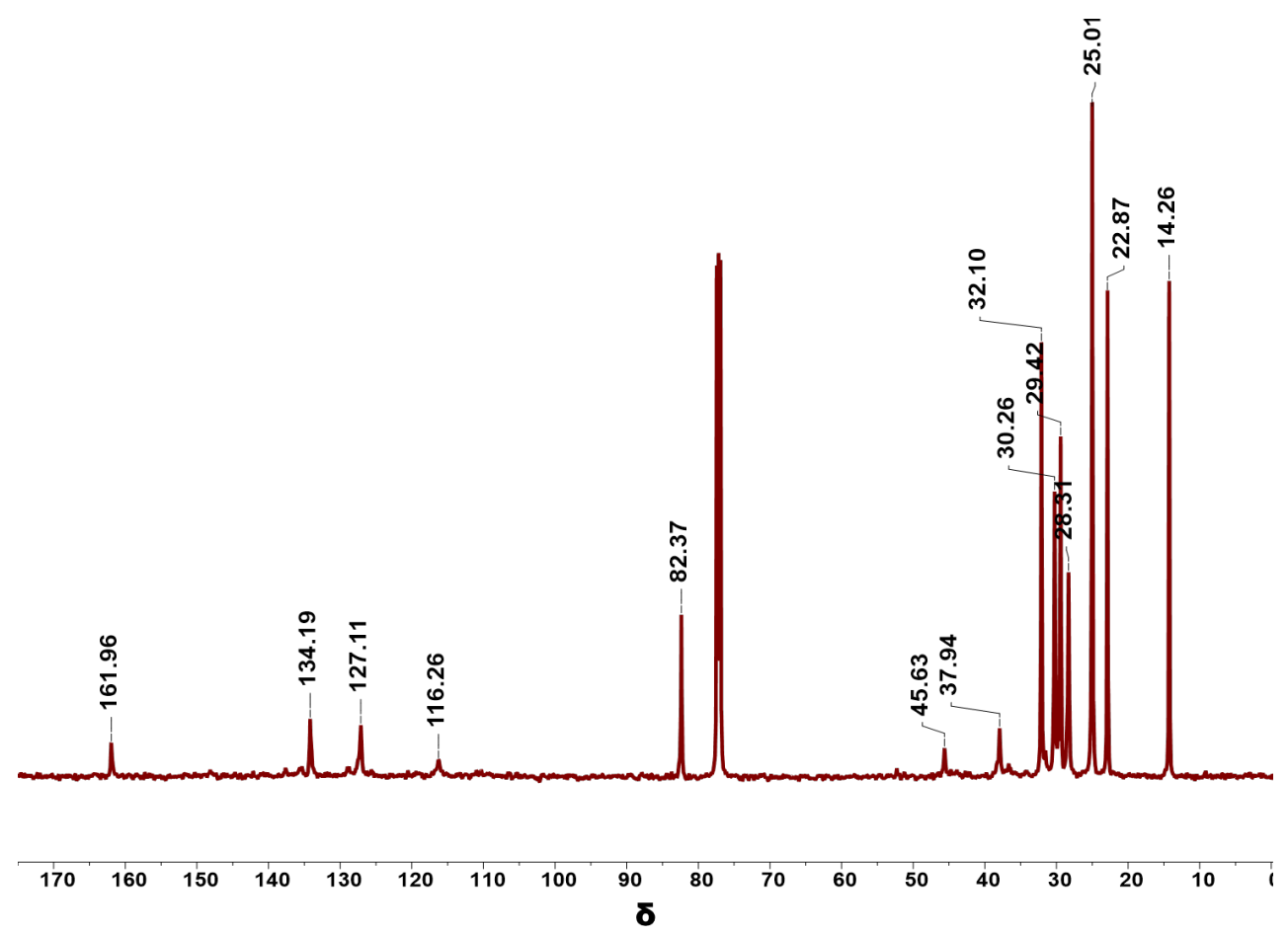

Figure S23: ${ }^{13} \mathrm{C}$ NMR Spectrum of Block Copolymer 6 in $\mathrm{CDCl}_{3}$

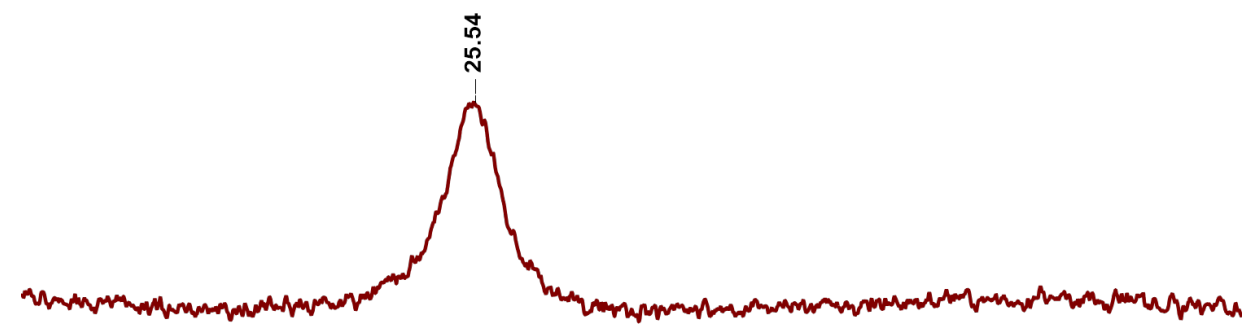

Figure S24: ${ }^{11} \mathrm{~B}$ NMR Spectrum of Block Copolymer 6 in $\mathrm{CDCl}_{3}$ 


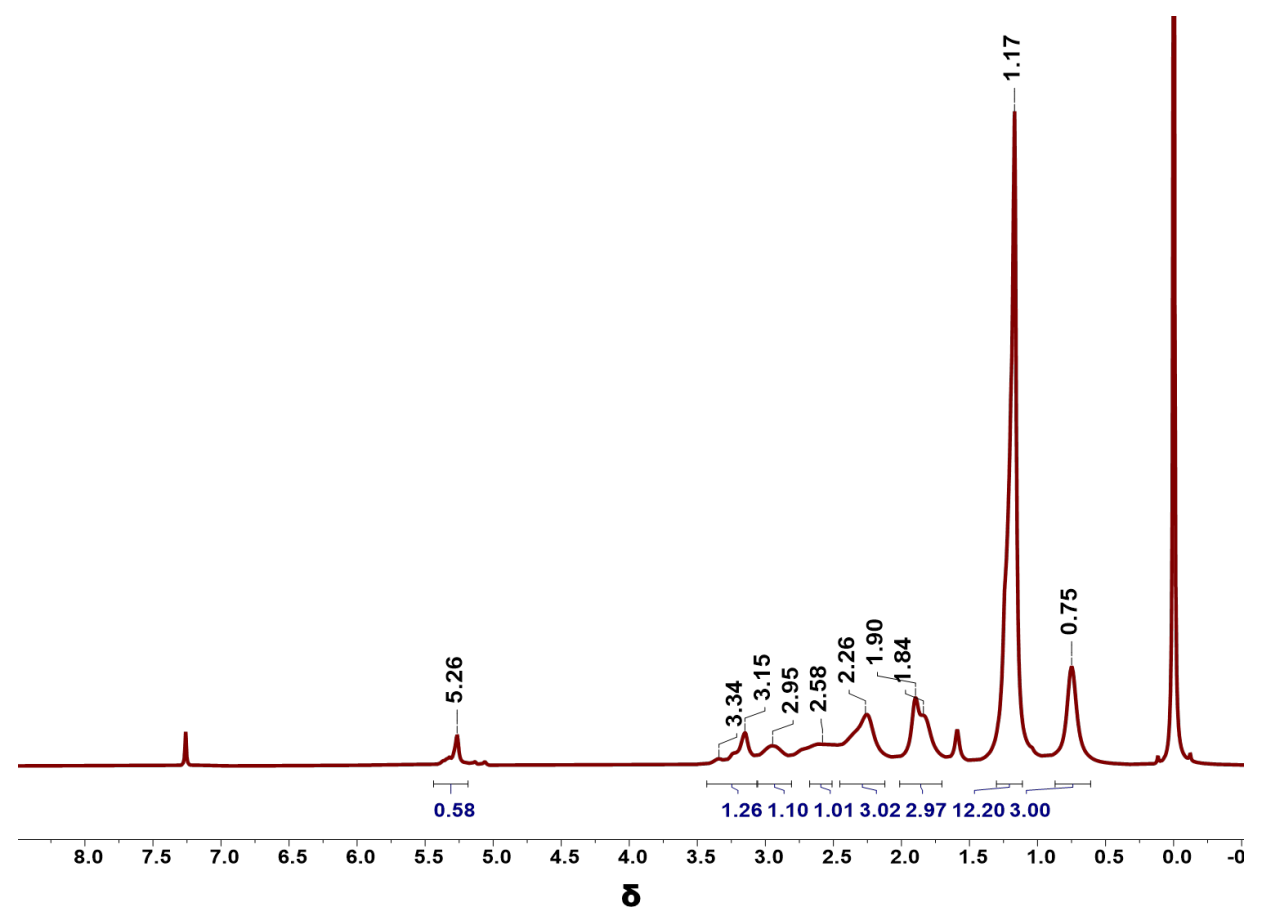

Figure S25: ${ }^{1} \mathrm{H}$ NMR Spectrum of Block Copolymer 7 in $\mathrm{CDCl}_{3}$
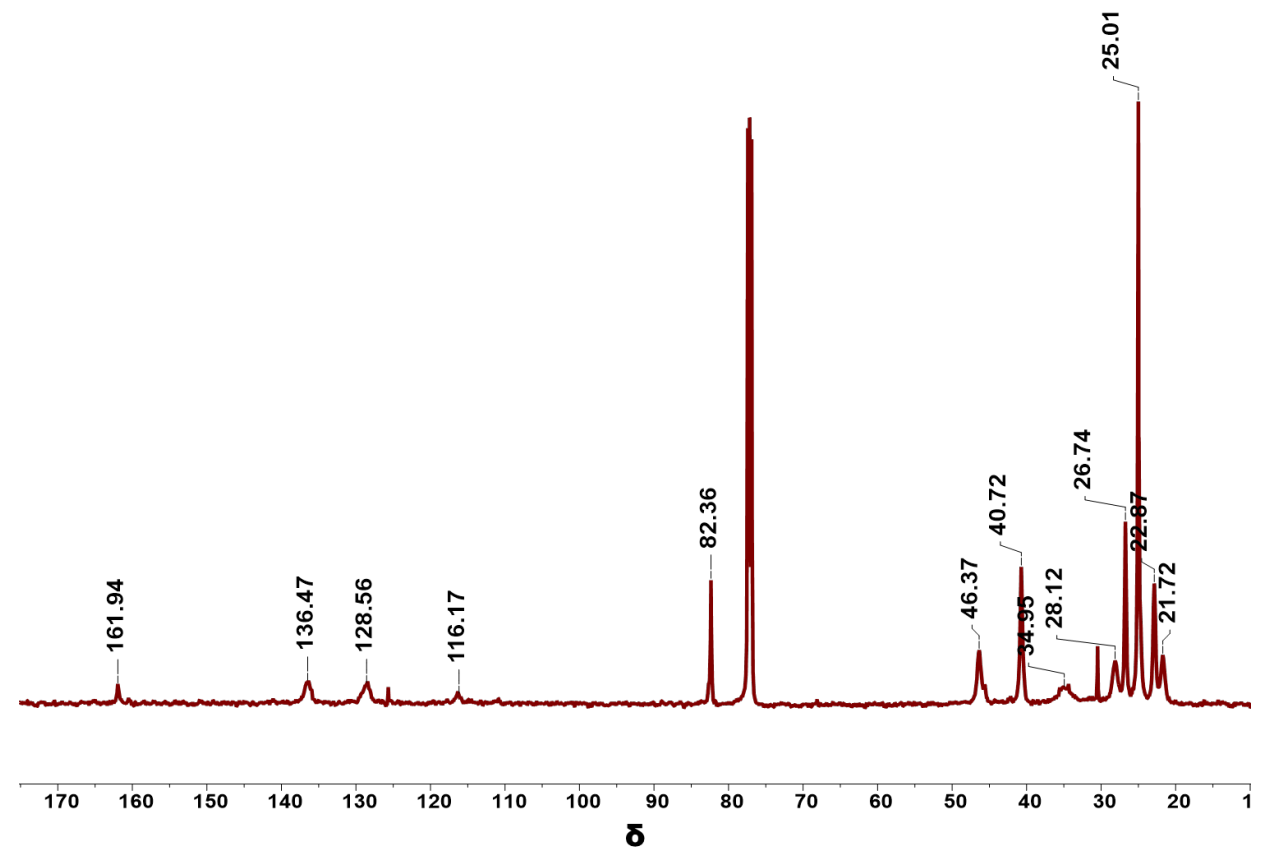

Figure S26: ${ }^{13} \mathrm{C}$ NMR Spectrum of Block Copolymer $\mathbf{7}$ in $\mathrm{CDCl}_{3}$ 

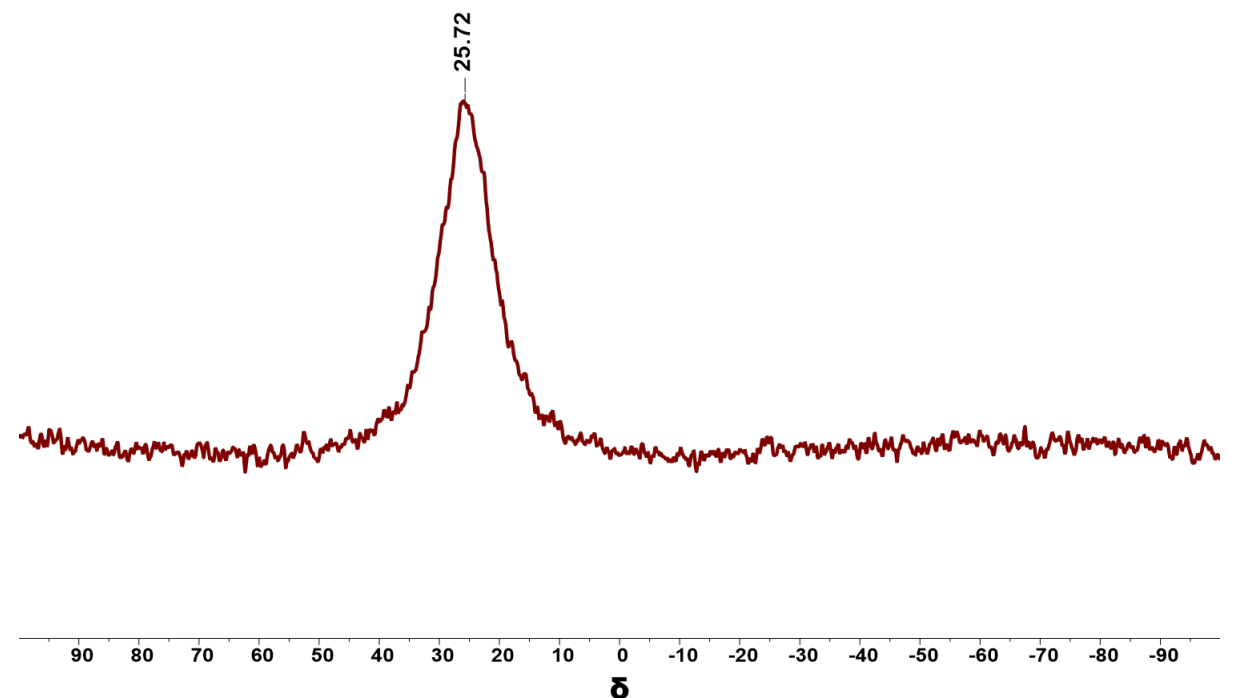

Figure S27: ${ }^{11} \mathrm{~B}$ NMR Spectrum of Block Copolymer 7 in $\mathrm{CDCl}_{3}$

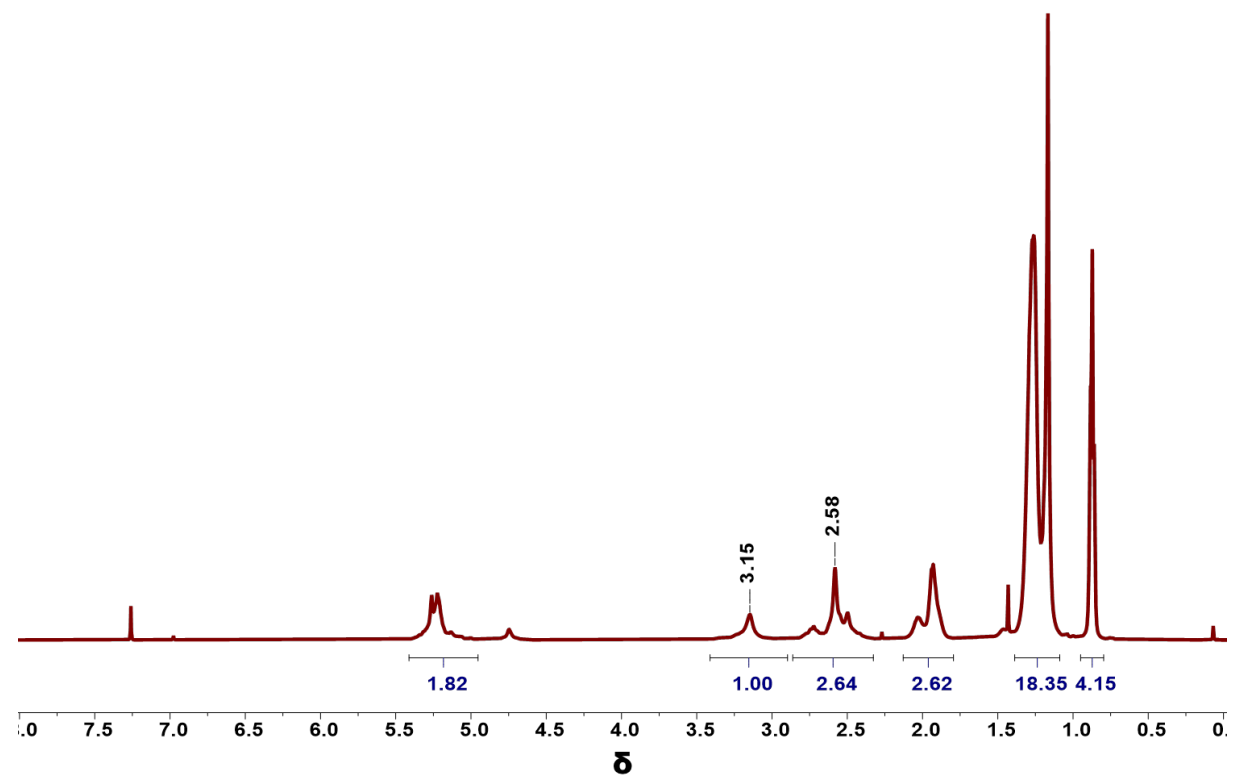

Figure S28: ${ }^{1} \mathrm{H}$ NMR Spectrum of 6 From Replicated Protocol in $\mathrm{CDCl}_{3}$ 


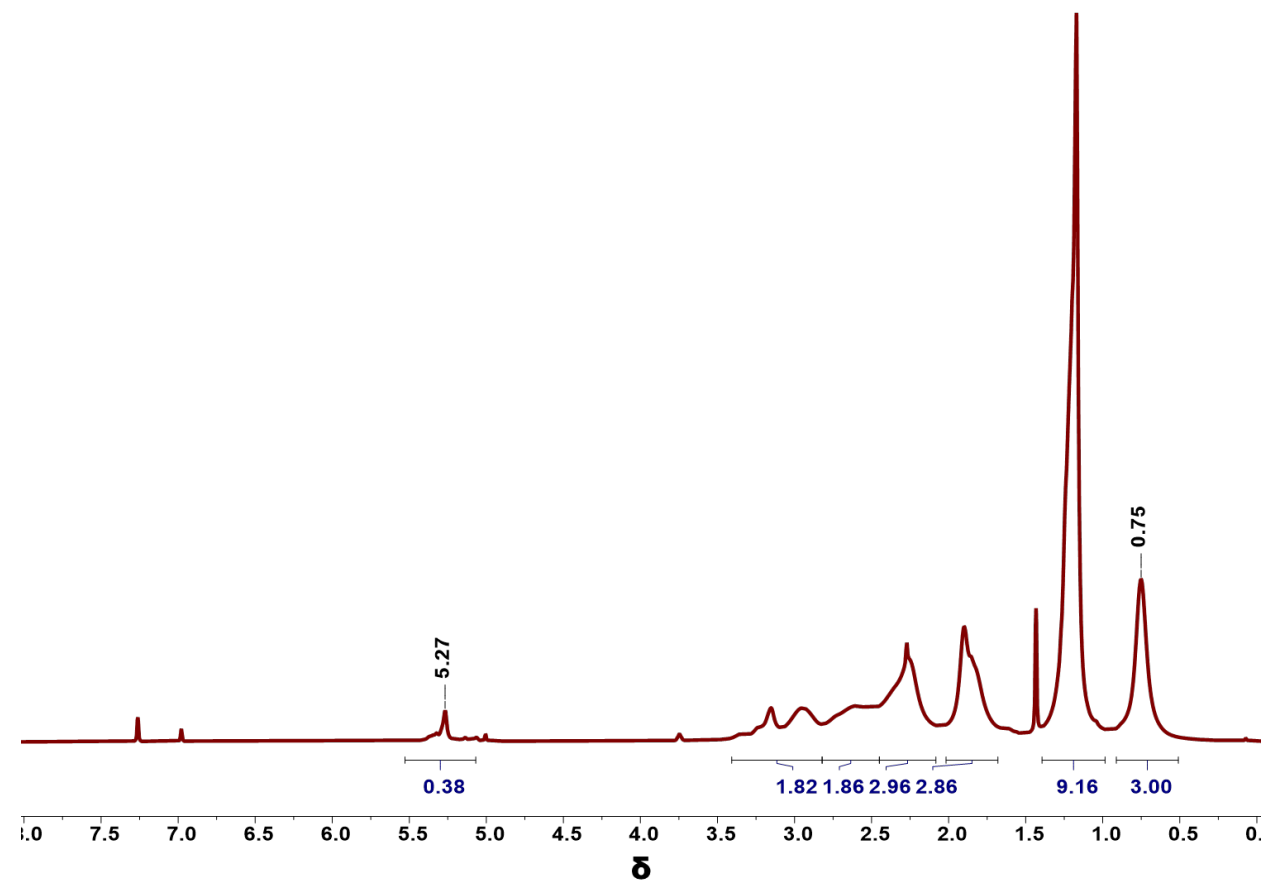

Figure S29: ${ }^{1} \mathrm{H}$ NMR Spectrum of 7 From Replicated Protocol in $\mathrm{CDCl}_{3}$

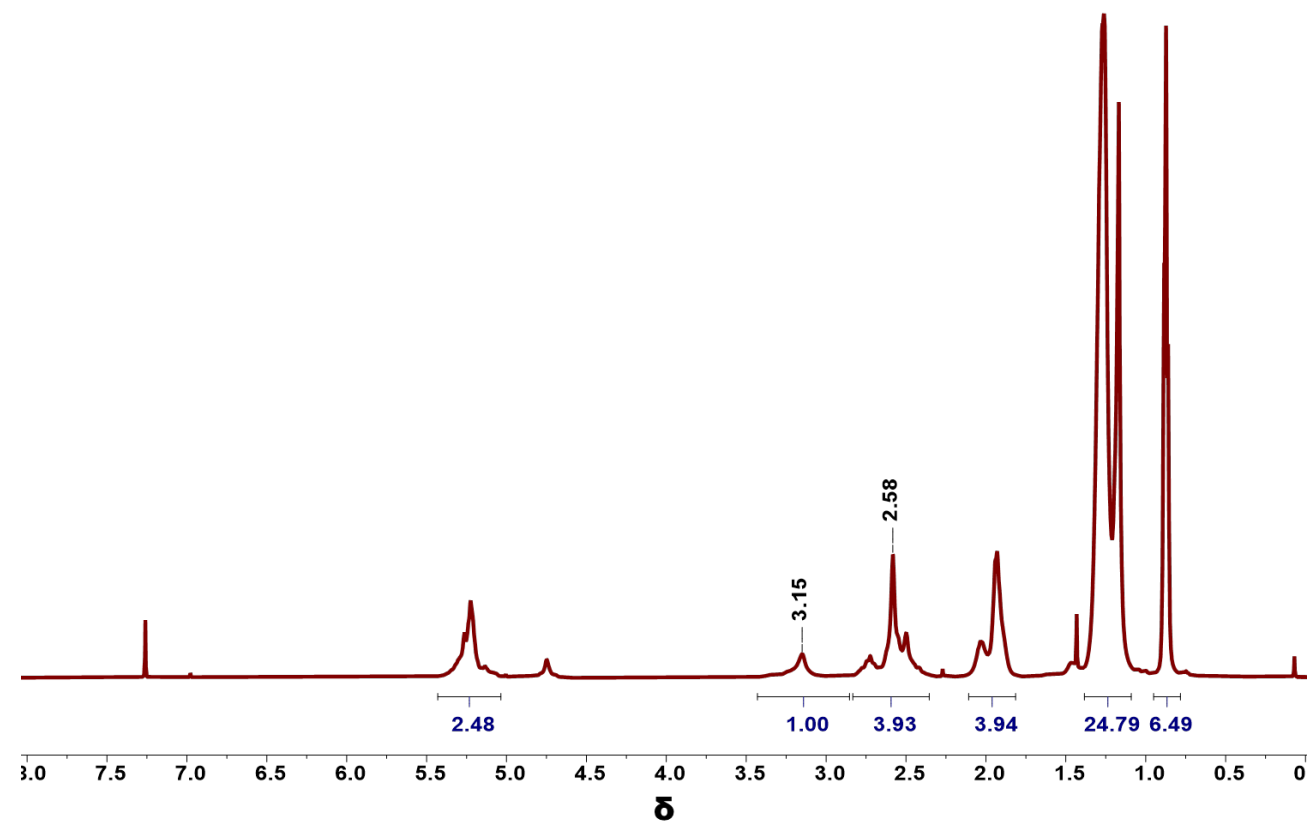

Figure S30: ${ }^{1} \mathrm{H}$ NMR Spectrum of 6 From Reversed Monomer Addition in $\mathrm{CDCl}_{3}$ 


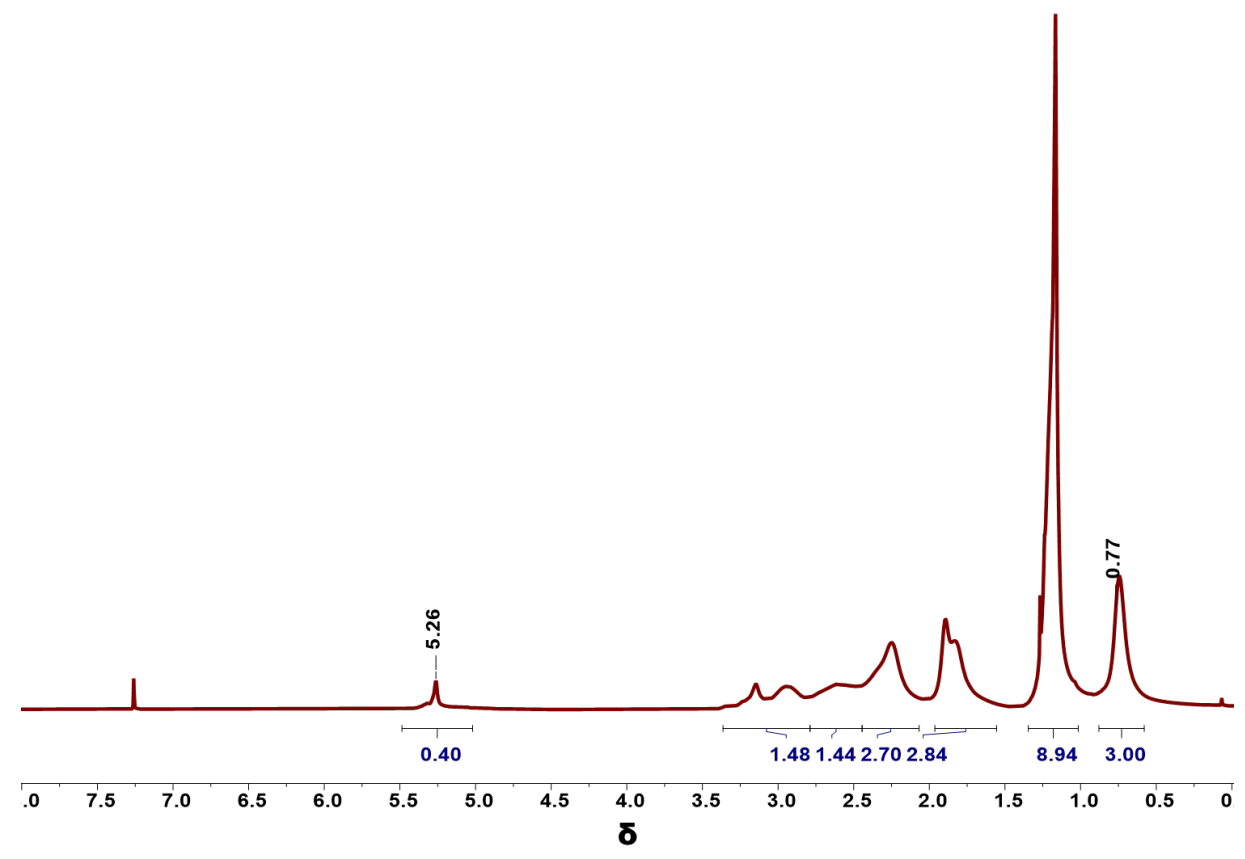

Figure S31: ${ }^{1} \mathrm{H}$ NMR Spectrum of 7 From Reversed Monomer Addition in $\mathrm{CDCl}_{3}$

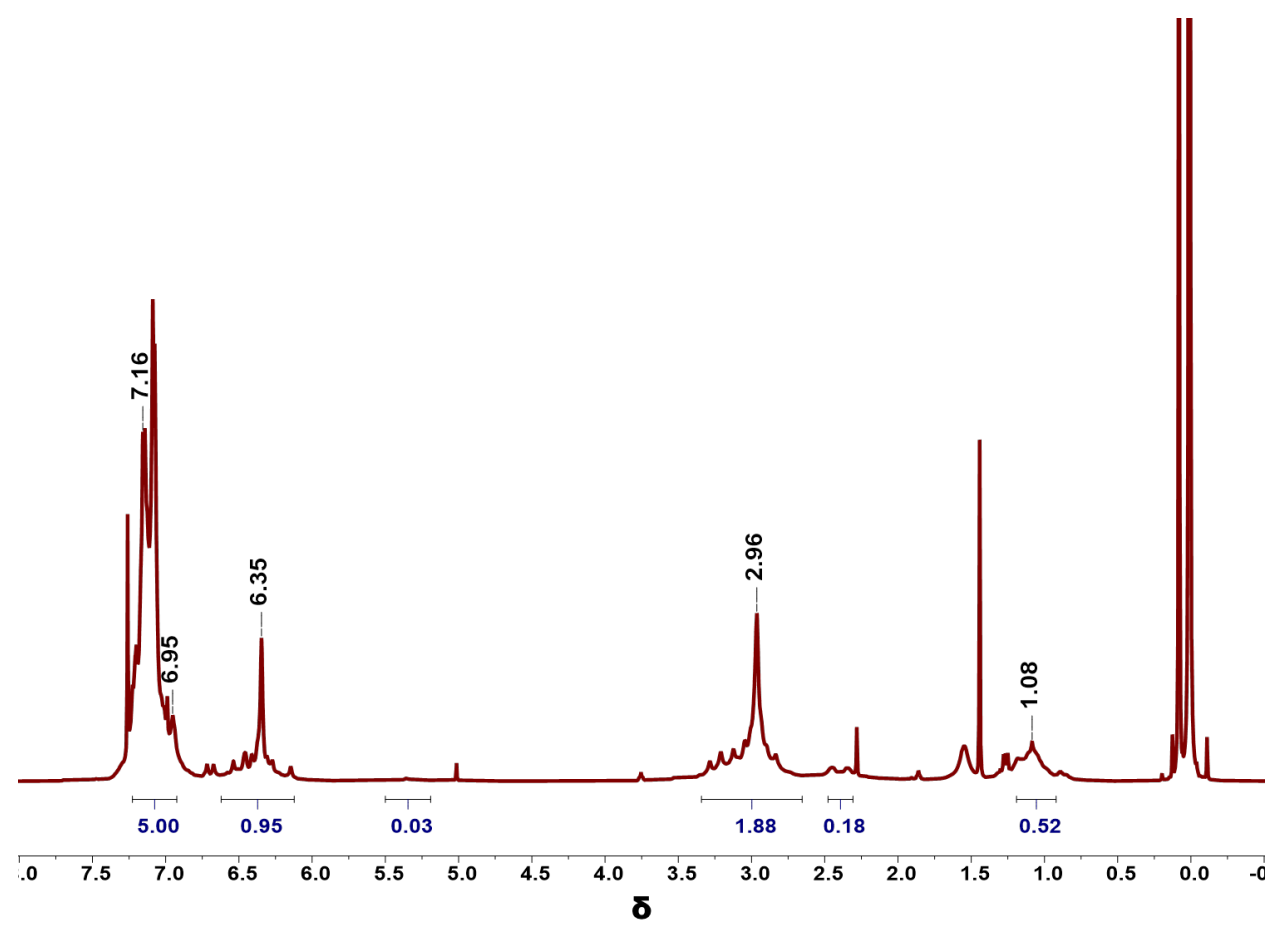

Figure S32: ${ }^{1} \mathrm{H}$ NMR Spectrum of Cross-Coupling Product 8 in $\mathrm{CDCl}_{3}$ 


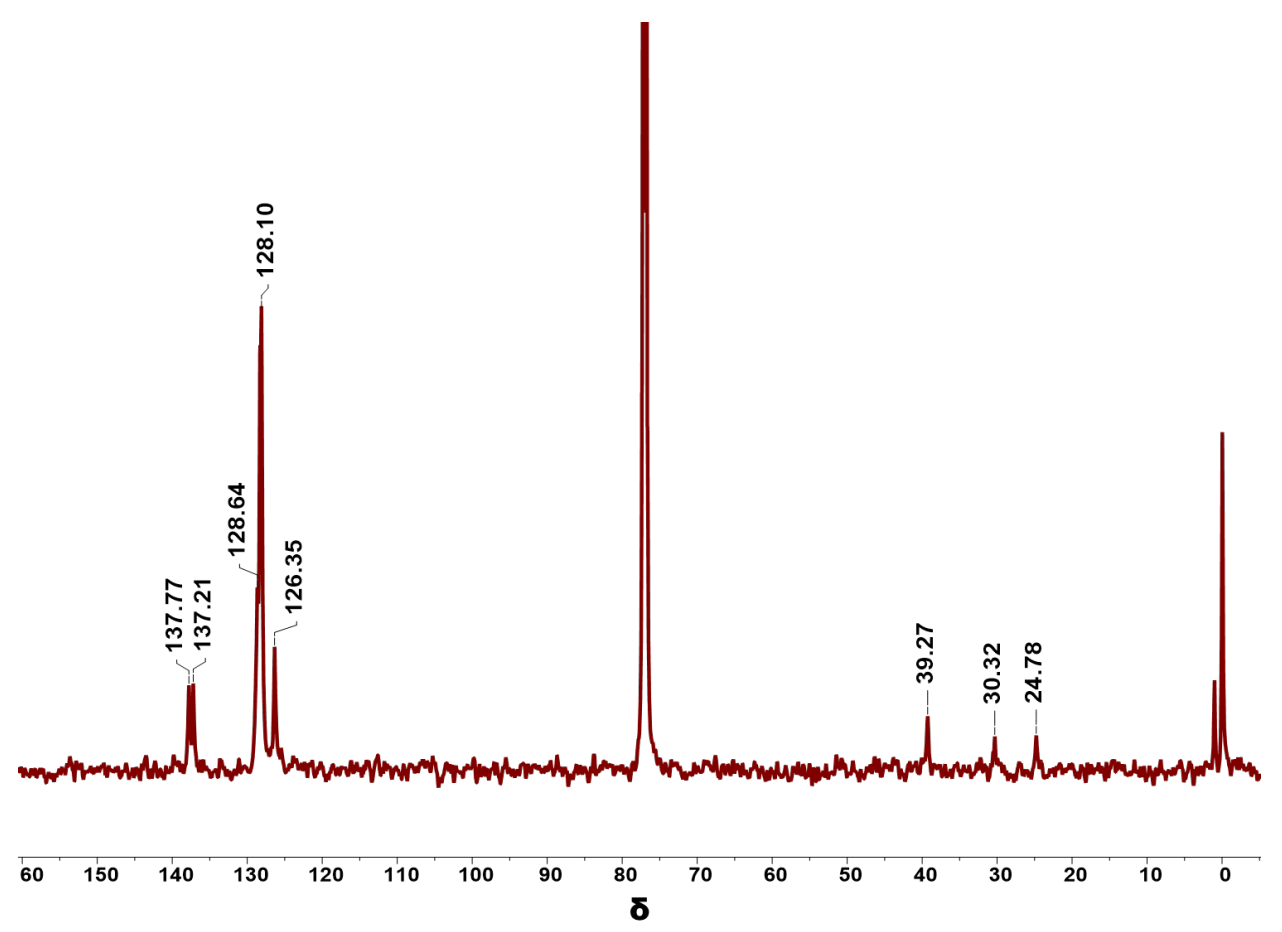

Figure S33: ${ }^{13} \mathrm{C}$ NMR Spectrum of Cross-Coupling Product 8 in $\mathrm{CDCl}_{3}$

\section{References}

(1) Bagutski, K.; Ros, A.; Aggarwal, V. K. Improved method for the conversion of pinacolboronic esters into trifluoroborate salts: facile synthesis of chiral secondary and tertiary trifluoroborates. Tetrahedron 2009, 65, 9956-9960.

(2) Gmernicki, K. R.; Hong, E.; Maroon, C. R.; Mahurin, S. M.; Sokolov, A. P.; Saito, T.; Long, B. K. Accessing Siloxane Functionalized Polynorbornenes via VinylAddition Polymerization for $\mathrm{CO}_{2}$ Separation Membranes. ACS Macro Lett. 2016, 5, 879-883.

(3) Galan, N. G.; Burroughs, J. M.; Maroon, C. R.; Long, B. K.; Brantley, J. N. Vinyladdition polymerizations of cycloallenes: synthetic access to congeners of cycloolefin monomers. Polm. Chem. 2020, 11, 5578-5581.

(4) Fried, A. D.; Brantley, J. N. Controlled Polymerization of $\beta$-Pinadiene: Accessing Unusual Polymer Architectures with Biomass-Derived Monomers. ACS Macro Lett. 2020, 9, 595-599.

(5) Takagi, K.; Tomita, I.; Endo, T. A Novel Living Coordination Polymerization of Phenylallene Derivatives by m-Allylnickel Catalyst. Macromolecules 1997, 30, 7386-7390. 
(6) Izunobi, J. U.; Higginbotham, C. L. Polymer Molecular Weight Analysis by ${ }^{1} \mathrm{H}$ NMR Spectroscopy. J. Chem. Educ. 2011, 88, 1098-1104.

(7) Jacobs, B. P.; Brantley, J. N. Exploring Combinatorial Approaches to Polymer Diversification. Macromolecules 2020, 53, 9287-9293. 